\title{
Effect of hygroscopic seeding on warm rain clouds - numerical study using a hybrid cloud microphysical model
}

\author{
N. Kuba ${ }^{1}$ and M. Murakami ${ }^{2}$ \\ ${ }^{1}$ Research Institute for Global Change, Japan Agency for Marine-Earth Science and Technology (JAMSTEC), \\ Yokohama, Japan \\ ${ }^{2}$ Meteorological Research Institute (MRI), Tsukuba, Japan \\ Received: 28 October 2009 - Published in Atmos. Chem. Phys. Discuss.: 12 November 2009 \\ Revised: 8 March 2010 - Accepted: 20 March 2010 - Published: 9 April 2010
}

\begin{abstract}
The effect of hygroscopic seeding on warm rain clouds was examined using a hybrid cloud microphysical model combining a Lagrangian Cloud Condensation Nuclei $(\mathrm{CCN})$ activation model, a semi-Lagrangian droplet growth model, and an Eulerian spatial model for advection and sedimentation of droplets. This hybrid cloud microphysical model accurately estimated the effects of $\mathrm{CCN}$ on cloud microstructure and suggested the following conclusions for a moderate continental air mass (an air mass with a large number of background $\mathrm{CCN}$ ). (1) Seeding can hasten the onset of surface rainfall and increase the accumulated amount of surface rainfall if the amount and radius of seeding particles are appropriate. (2) The optimal radius of monodisperse particles to increase rainfall becomes larger with the increase in the total mass of seeding particles. (3) Seeding with salt micro-powder can hasten the onset of surface rainfall and increase the accumulated amount of surface rainfall if the amount of seeding particles is sufficient. (4) Seeding by a hygroscopic flare decreases rainfall in the case of large updraft velocity (shallow convective cloud) and increases rainfall slightly in the case of small updraft velocity (stratiform cloud). (5) Seeding with hygroscopic flares including ultragiant particles $(r>5 \mu \mathrm{m})$ hastens the onset of surface rainfall but may not significantly increase the accumulated surface rainfall amount. (6) Hygroscopic seeding increases surface rainfall by two kinds of effects: the "competition effect" by
\end{abstract}

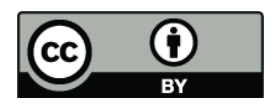

Correspondence to: N. Kuba (kuba@jamstec.go.jp) which large soluble particles prevent the activation of smaller particles and the "raindrop embryo effect" in which giant soluble particles can immediately become raindrop embryos. In some cases, one of the effects works, and in other cases, both effects work, depending on the updraft velocity and the amount and size of seeding particles.

\section{Introduction}

Hygroscopic seeding to promote water droplet coalescence by introducing appropriately sized salt particles, sprayed water droplets, or saline solution into clouds has long been known and used (Bowen, 1952; Biswas and Dennis, 1971; Cotton, 1982; Murty et al., 2000). In classic hygroscopic seeding approaches, large hygroscopic particles at least $10 \mu \mathrm{m}$ in diameter are used to provide raindrop embryos. This method requires that a huge amount of seeding material be dispersed by aircraft. Drawbacks of this method include its inconvenience for practical use, low cost-effectiveness, and possible adverse effects of salt on the environment.

Hygroscopic seeding with flares, which produces salt particles 0.3 to $10 \mu \mathrm{m}$ in diameter, has been used to augment precipitation from summertime convective clouds in South Africa and Mexico, with promising results indicated by radar-estimated rainfall (Mather et al., 1997; WMO, 2000). The flare method has been widely used in a number of countries and regions because of its convenience for field operations and the abovementioned promising experimental results. However, results regarding seeding effects are

Published by Copernicus Publications on behalf of the European Geosciences Union. 
inconclusive due to the lack of understanding of the physical processes leading to increases in radar-estimated rainfall.

To investigate the effects of hygroscopic seeding on cloud and precipitation, many studies have applied numerical models. Reisin et al. (1996) simulated hygroscopic seeding of an axisymmetric convective cloud and showed that seeding had a dramatic effect on rainfall. They determined the cloud droplet number by Cloud Condensation Nuclei (CCN) activation spectra and distributed the droplets over size bins according to a gamma or exponential function. However, by this method, the effect of hygroscopic seeding on the initial size distribution of cloud droplets could not be shown clearly.

Tzivion et al. (1994) applied an axisymmetric convective cloud model with detailed treatment of warm cloud microphysics to estimate the effect of hygroscopic seeding, which was represented by added water droplets. Yin et al. (2000) conducted numerical experiments to evaluate the role of hygroscopic flare seeding using a two-dimensional (2D) slab-symmetric non-hydrostatic cloud model with a detailed microphysical scheme. They found that seeding with the full particle spectrum from flares could increase the rainfall amount in continental clouds having $\mathrm{CCN}$ concentrations more than $\sim 500 \mathrm{~cm}^{-3}$ (active at $1 \%$ supersaturation). Teller and Levin (2006) also carried out numerical experiments using the Tel-Aviv University two-dimensional numerical cloud model with detailed treatment of cloud microphysics. Their results showed that giant CCN enhanced the total precipitation on the ground in polluted clouds. However, in the models of Tzivion et al. (1994), Yin et al. (2000), and Teller and Levin (2006), grid sizes ranged from 150 300 m in the vertical direction, which is not small enough to estimate the maximum supersaturation that significantly affects $\mathrm{CCN}$ activation. To precisely estimate the activation of $\mathrm{CCN}$, an Eulerian spatial framework with a very small grid size or a Lagrangian particle framework as a parcel model is needed (Kuba and Fujiyoshi, 2006).

Cooper et al. (1997) and Caro et al. (2002) investigated the effect of flare hygroscopic seeding using a parcel model with a precise microphysical model. Their calculations suggested that rain formation via the collision-coalescence process can be accelerated significantly by adding hygroscopic particles. Segal et al. $(2004,2007)$ investigated the effect of hygroscopic seeding on warm rain using a 2000-bin cloud spectral parcel model. Their simulations showed that use of commercial hygroscopic flares increased raindrop production in cloud parcels in which the natural warm rain process was inefficient. They also found that the optimum seeding particle radius that provided the maximum raindrop production under a given mass of seeding reagent varied from 1.5 to $2.5 \mu \mathrm{m}$ and slightly depended on the total reagent mass as well as the dynamic properties of cloud parcels. In addition, they found that the main effect of large soluble aerosols, which are activated at supersaturation $<0.004 \%$ and belong to the coarse aerosol mode, was to form raindrop embryos, revealing the embryo effect, not the competition effect (whereby large soluble particles prevent activation of smaller or less soluble particles). However, estimation of surface rainfall using the parcel model appears to be difficult.

The competition effect was emphasized by Ghan et al. (1998) and O'Dowd et al. (1999) and discussed in Feingold and Siebert (2009). Appropriate number concentrations of seeding particles compete with the background CCN for available excess water vapor and consequently lower the maximum supersaturation, decrease the number concentrations of activated cloud droplets, and increase the droplet sizes, which enhances collision-coalescence among cloud droplets and accelerates the formation of raindrop embryos. It is important to study what condition gives the embryo effect, the competition effect, or both of them for estimation of the effect of hygroscopic seeding.

The purpose of the present study was to quantitatively evaluate the effect of hygroscopic seeding on surface rainfall from shallow warm rain clouds using a hybrid cloud microphysical model that incorporates a Lagrangian $\mathrm{CCN}$ activation model, a semi-Lagrangian droplet growth model, and an Eulerian spatial model for advection and sedimentation of droplets (Kuba and Fujiyoshi, 2006). This model can simulate the $\mathrm{CCN}$ activation process precisely so that the effect of a slight change in the initial cloud droplet size distribution due to hygroscopic seeding can be evaluated in detail. The model can also accurately calculate the consequent droplet growth through condensation and collision-coalescence as well as advection, size sorting, and sedimentation of drops in clouds, producing a reliable estimate of the seeding effect on surface precipitation. Because a kinematic flow field is assumed in this simple model, dynamical feedbacks associated with microphysical changes due to varying CCN cannot be simulated. These effects will be studied by installing our hybrid cloud microphysical model into a nonhydrostatic cloud model in future research. The simulations were performed for shallow convective and stratiform clouds with moderate continental background CCN. Seeding particles used in the present simulations had monodisperse, single log-normal (salt micro-powder) and double log-normal (hygroscopic flare) size distributions.

\section{Model description}

The hybrid microphysical cloud model was developed to accurately estimate the number concentration and size distribution of cloud droplets and the effect of $\mathrm{CCN}$ on cloud microstructures (Kuba and Fujiyoshi, 2006). The activation of $\mathrm{CCN}$ and initial condensational growth are computed in a Lagrangian particle framework using a parcel model. The solute effect of CCN is taken into account even after the activation. Because the maximum supersaturation experienced by an air parcel is estimated accurately, the number of cloud droplets that can be activated is also estimated accurately. This method precludes numerical diffusion of the droplet size 
distribution. A time step of $0.05 \mathrm{~s}$ is adopted for the parcel model to calculate $\mathrm{CCN}$ activation and the consequent condensational growth of droplets. This hybrid cloud microphysical model also uses a two-moment bin method based on that of Chen and Lamb (1994) in a 2-D grid model to estimate condensation and coalescence with a semi-Lagrangian framework and to estimate sedimentation and advection with an Eulerian spatial framework. The cloud droplet size distribution estimated by the parcel model is used as the initial cloud droplet size distribution for the two-moment bin method. This method for giving the initial cloud droplet size distribution seems to be preferable to previously used methods in which activated droplets were added to the first bin (Morrison and Grabowski, 2007; Grabowski and Wang, 2009) or distributed to bins assuming some size distribution shapes (Tzivion et al., 1994; Reisin et al., 1996). Details of the model have been reported by Kuba and Fujiyoshi (2006).

The present study made the following improvements to the hybrid microphysical cloud model of Kuba and Fujiyoshi (2006). To properly estimate multi-coalescence in one time step, two schemes are used. One is a general stochastic coalescence scheme for rare lucky coalescence between droplets, and the other is a continuous coalescence scheme for frequent coalescence of a large drop and numerous small droplets (numerous small droplets are evenly shared by large drops) following the method reported in the doctoral dissertation of Jen-Ping Chen (1992). We distinguish rare lucky coalescence and frequent coalescence using the predicted frequency of collision in one time step. If the predicted frequency of collision between one particle in the $i$-th bin and smaller particles in the $k$-th, $(k+1)$-th, ..., and $i$-th bins in one time step is 1 or less, a general stochastic coalescence scheme is used to calculate the growth of particles in the $i$-th bin by coalescence with particles in the $k$ th, $(k+1)$-th, ..., and $i$-th bins. If the predicted frequency of collision of one particle in the $i$-th bin and smaller particles in the first, second, ..., and $i$-th bins in one time step is larger than 1, a continuous coalescence scheme is used to calculate the growth of particles in the $i$-th bin by coalescence with particles in the first, second, ..., and $(k-1)$-th bins (see Appendix for details). If only the general stochastic coalescence scheme is used, a very short time step such as $0.01 \mathrm{~s}$ is needed to avoid underestimation of coalescence growth caused by the underestimation of multiple coalescences. This method using both continuous and stochastic schemes with a time step of $3.0 \mathrm{~s}$ leads to the same results as the method using only the stochastic scheme with a time step of $0.01 \mathrm{~s}$, as shown in the Appendix (Fig. A1). However, in this study, a $0.5 \mathrm{~s}$ time step is adopted for the bin method considering other conditions. We use 73 bins to express a range of radii (from $1 \mu \mathrm{m}$ to $4 \mathrm{~mm}$ ) for activated cloud droplets and raindrops. In addition, we adopt the coalescence efficiency proposed by Seifert et al. (2005) and a breakup scheme based on that of Feingold et al. (1988) to estimate the collision-breakup of raindrops. Collision-coalescence and collision-breakup are calculated separately. In the calculation of breakup, all collisions are treated as stochastic coalescence. This is obviously a contradictory treatment, as continuous and stochastic schemes are used in the calculation of collision-coalescence. In the calculation of breakup, using only a stochastic scheme seems to cause some underestimation of the efficiency of breakup following multi-coalescence in one time step. However, the probability of breakup following the collision between a large drop and numerous small droplets is very small. Hence the method in this study can provide quite accurate results.

\section{Numerical experiments}

The kinematic framework of this study is based on that used by Szumowski et al. (1998) to test the warm rain microphysical model. The kinematic cloud model prescribes an evolving flow and performs 2-D advection of temperature and water variables (domain: $9 \mathrm{~km} \times 3 \mathrm{~km}, \mathrm{dx}$ and dz: $50 \mathrm{~m}$, dt: $3 \mathrm{~s}$ ). The flow pattern shows low-level convergence, upper-level divergence, and a narrow updraft located in the center of the domain. The magnitude, vertical structure, width, and tilt of the flow through the central updraft are all prescribed using simple analytical functions. This kinematic framework with a microphysical scheme predicts temporal and spatial evolution of water vapor, hydrometeors, and potential temperature explicitly by using the prescribed flow field and initial and boundary conditions of water vapor content and potential temperature. The advection scheme is a modified version of that of Smolarkiewicz (1984). The bulk microphysical scheme incorporated in Szumowski's original model is replaced with our hybrid microphysical model (Kuba and Fujiyoshi, 2006). This simple model cannot estimate the effect of rainfall-induced drag on dynamics. The effect of change in drag caused by differences in $\mathrm{CCN}$ will be studied in future work. However, the model can estimate the effects of CCN on the cloud microstructure and raindrop formation. Therefore, this model is suitable for estimating the effect of hygroscopic seeding on warm rain formation. This model takes the effect of updraft velocity into account, but it cannot take the effect of geographic location into account. These effects cannot be neglected and will be studied by installing our hybrid cloud microphysical model into a non-hydrostatic cloud model in the future.

Figure 1 shows the initial state of potential temperature and the mixing ratio of water vapor. Figure 2 presents the time evolution of updraft velocity near the cloud center for the shallow convective cloud case (a) and for the stratiform cloud case (b). Seeding is assumed to be carried out from an airplane under the cloud base in this study. Other methods (at the cloud top or in the cloud) will be considered in a future study. Our preliminary numerical experiments using the hybrid microphysical cloud model suggested that later timing of seeding leads to a smaller effect on precipitation. Therefore, 


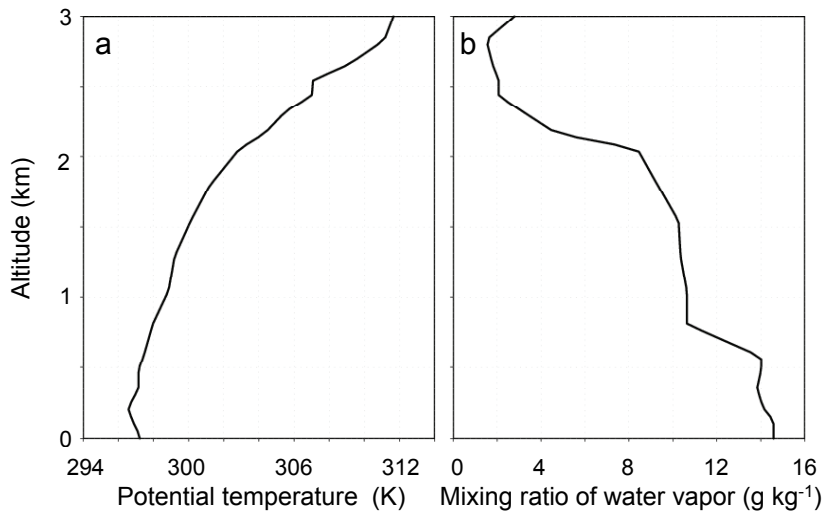

Fig. 1. Initial state of the (a) potential temperature (K) and (b) mixing ratio of water vapor $\left(\mathrm{g} \mathrm{kg}^{-1}\right)$.

the hygroscopic seeding is assumed to begin 5 min after cloud initiation. Seeding durations are $10 \mathrm{~min}$ for the shallow convective cloud case and $95 \mathrm{~min}$ for the stratiform cloud case. These durations result in the same seeded volumes in the clouds or the same total amounts of seeding particles for the two cloud types. Figure 3 shows the wind field at the time of peak updraft velocity for the shallow convective cloud case (a) and the stratiform cloud case (b).

Kuba and Takeda (1983), Cooper et al. (1997), Feingold et al. (1999), and Saleeby and Cotton (2004) showed that giant $\mathrm{CCN}$ have the greatest effect on the precipitation efficiency of warm rain clouds in cases with numerous small background $\mathrm{CCN}$. When low concentrations of small $\mathrm{CCN}$ are present, adding giant $\mathrm{CCN}$ results in a slight decrease in rainfall, suggesting that almost all rainwater is produced by condensation onto small CCN. On the other hand, when high concentrations of small $\mathrm{CCN}$ are present, adding giant $\mathrm{CCN}$ leads to a modest increase in rainfall amount, suggesting that rainwater is produced mainly from condensation onto giant $\mathrm{CCN}$ and small cloud droplets caught by large droplets condensed on giant CCN (Kuba and Fujiyoshi, 2006). Preliminary numerical experiments using our hybrid microphysical cloud model (not shown here) also suggested that hygroscopic seeding cannot increase warm rain when the number concentration of background $\mathrm{CCN}$ is low (the size distribution of maritime background $\mathrm{CCN}$ used in preliminary numerical experiments is shown by the purple line in Fig. 4). Therefore, it is assumed that $\mathrm{CCN}$ for the non-seeded case (reference case) consist of high concentrations of small particles like a continental case or polluted case. To clearly estimate the role of seeding particles, the number concentration of large $\mathrm{CCN}$ is assumed to be very small (e.g., the number concentrations are $2.0 \mathrm{e}-5 \mathrm{~cm}^{-3}$ for $\mathrm{CCN}$ larger than $1 \mu \mathrm{m}$ in radius and $5.0 \mathrm{e}-7 \mathrm{~cm}^{-3}$ for $\mathrm{CCN}$ larger than $5 \mu \mathrm{m}$ in radius). The chemical composition of these $\mathrm{CCN}$ is assumed to be $\mathrm{NaCl}$. The $\mathrm{CCN}$ size distribution for the non-seeded case (background $\mathrm{CCN}$ ) is shown by the red line in Fig. 4.
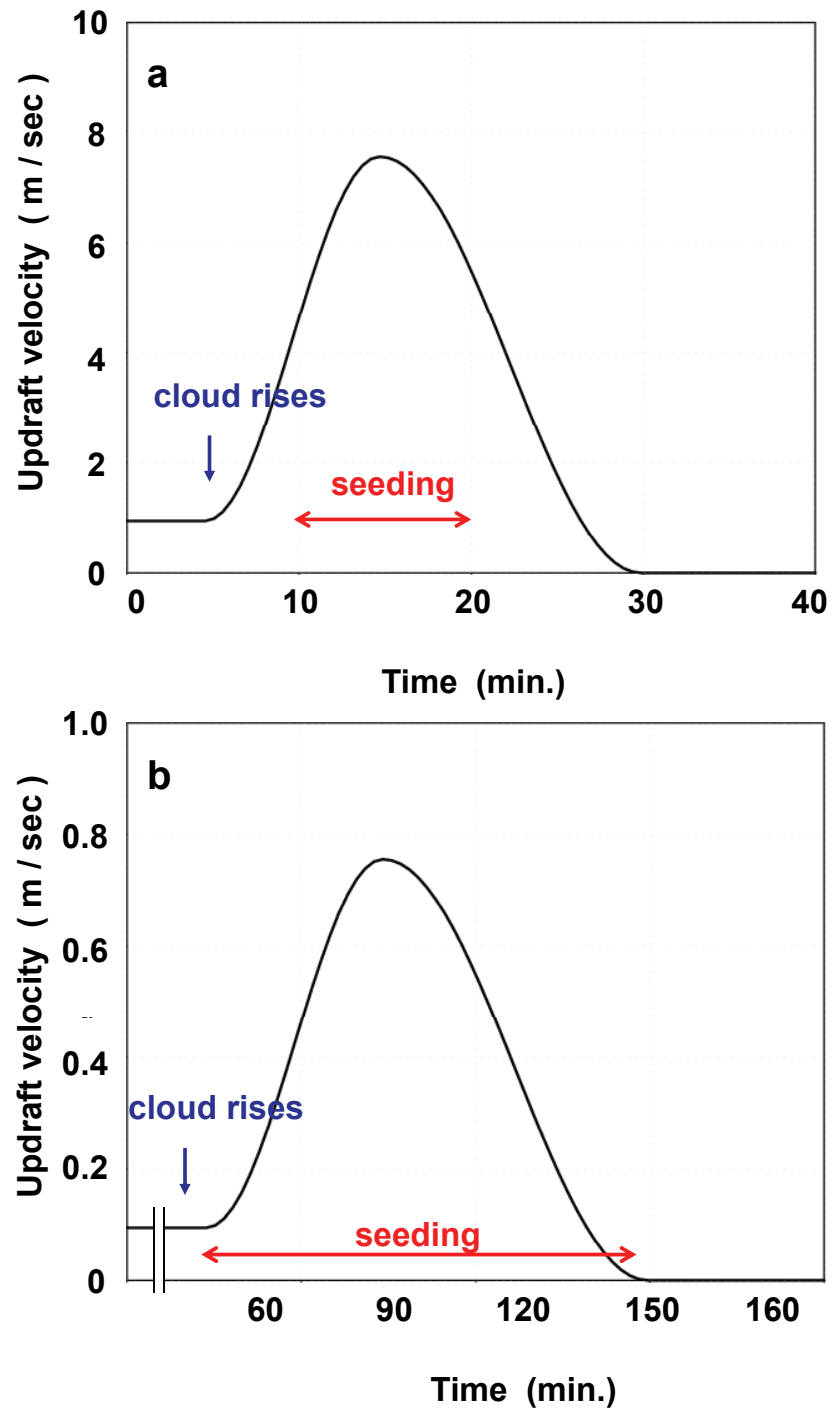

Fig. 2. Time evolution of updraft velocity near the center of the cloud for the shallow convective cloud case (a) and for the stratiform cloud case (b).

We use 181 classes to express a range of radii (from 0.009 to $9 \mu \mathrm{m})$ for background CCN. Figure 5 shows cloud water in the non-seeded case for convective cloud at $15 \mathrm{~min}(10 \mathrm{~min}$ after cloud initiation) and stratiform cloud at $80 \mathrm{~min}$ (30 min after cloud initiation).

\subsection{Hygroscopic seeding with monodisperse particles}

To estimate the most efficient radius and amount of seeding particles, monodisperse $\mathrm{NaCl}$ particles are used as seeding particles. Number concentrations of seeding particles under the cloud base for 20 cases, including five different radii and four different total masses of seeding particles, are shown in Table 1. 


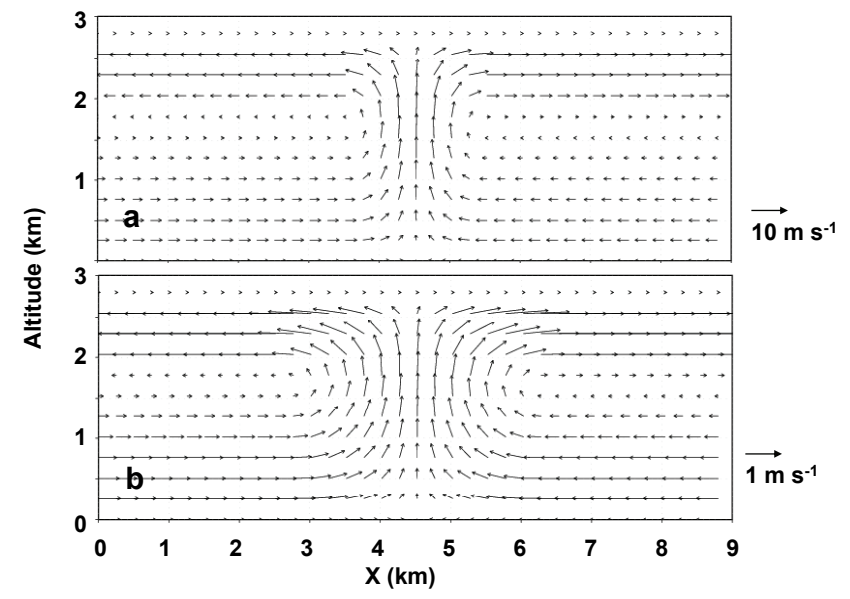

Fig. 3. The wind field at the time of peak updraft velocity for the shallow convective cloud case (a) at $15 \mathrm{~min}$ and for the stratiform case (b) at $90 \mathrm{~min}$ ).

Table 1. Number concentrations $\left(\mathrm{cm}^{-3}\right)$ of seeding particles under the cloud base in 20 cases including five different radii and four different total amounts of seeding particles. The reference total amount of seeding particles (ratio =1) is $2.83 \times 10^{-4} \mathrm{~g} \mathrm{~m}^{-3}$.

\begin{tabular}{ccccc}
\hline & \multicolumn{5}{c}{ Ratio of total amount of seeding particles } \\
\cline { 2 - 5 } Radius of seeding particles & 0.1 & 0.5 & 1 & 10 \\
\hline $0.25 \mu \mathrm{m}$ & 200 & 1000 & 2000 & 20000 \\
$0.50 \mu \mathrm{m}$ & 25 & 125 & 250 & 2500 \\
$1.00 \mu \mathrm{m}$ & 3.125 & 15.63 & 31.25 & 312.5 \\
$2.50 \mu \mathrm{m}$ & 0.2 & 1.0 & 2.0 & 20 \\
$5.00 \mu \mathrm{m}$ & 0.025 & 0.125 & 0.25 & 2.5 \\
\hline
\end{tabular}

\subsubsection{Convective cloud case}

This section presents results of seeding the shallow convective cloud (Figs. 2a and 3a) with monodisperse particles. Figure 6a shows the cloud droplet size distributions at $100 \mathrm{~m}$ above the base of the cloud center (updraft velocity is approximately $\left.4 \mathrm{~ms}^{-1}\right)$ at $11.5 \mathrm{~min}(90 \mathrm{~s}$ after the start of seeding) for the non-seeded case and seeded cases with the reference total mass of seeding particles ("ratio" $=1$ in Table 1). The radii of seeding particles in each seeding case are $0.25,0.5,1.0,2.5$, or $5.0 \mu \mathrm{m}$. Droplets condensed on seeding particles stand out for each seeded case. The results also show that seeding with small particles $(0.25$ and $0.5 \mu \mathrm{m}$ in radius) decreases the mode radius of cloud droplets condensed on background CCN. On the other hand, seeding with large particles $(1.0,2.5$, or $5.0 \mu \mathrm{m})$ does not significantly affect the mode radius of cloud droplets condensed on background $\mathrm{CCN}$.

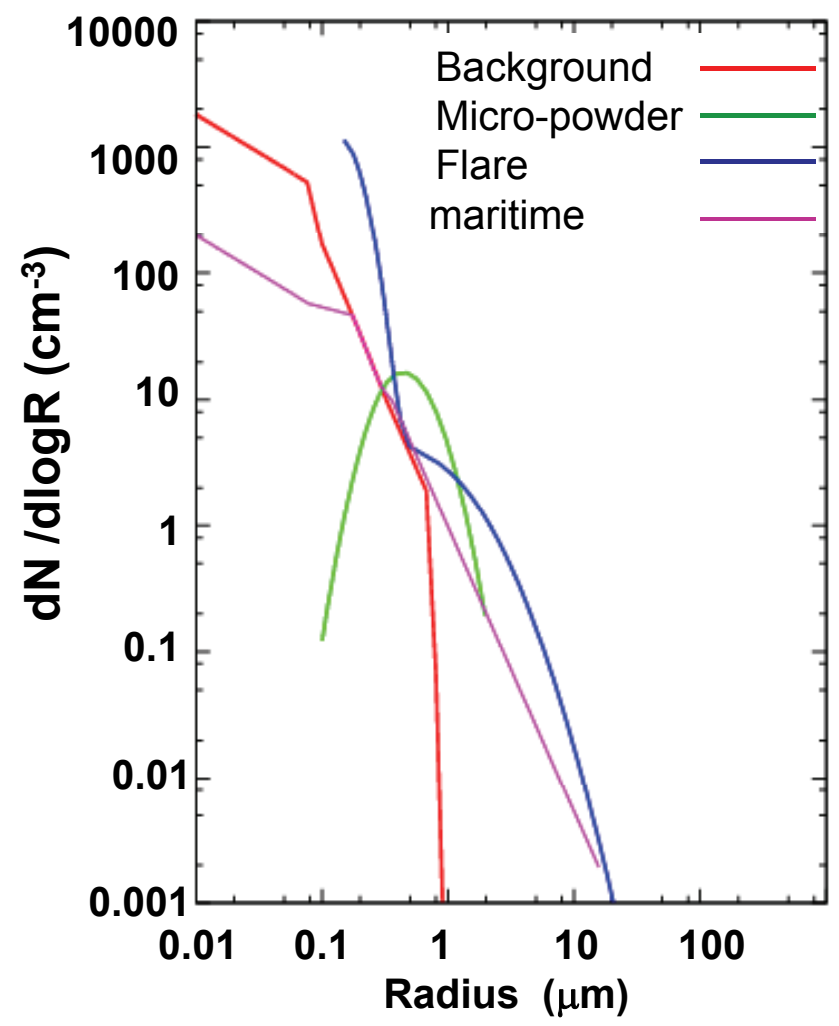

Fig. 4. Size distributions of the background CCN (red line), salt micro-powder (green line), and hygroscopic flare particles (blue line). Total number concentration of background CCN $(r>0.01 \mu \mathrm{m})$ is $1000 \mathrm{~cm}^{-3}$. Those of seeding particles shown by size distributions in green and blue are $90 \mathrm{~cm}^{-3}$ and $970 \mathrm{~cm}^{-3}$, respectively. Maritime background $\mathrm{CCN}$, which was used in preliminary numerical experiments, is also shown in this figure. The total number concentration of maritime background $\mathrm{CCN}(r>0.01 \mu \mathrm{m})$ is $140 \mathrm{~cm}^{-3}$.

Figure 7 shows temporal change in accumulated surface rainfall averaged over the domain. The black solid line in each panel indicates accumulated rainfall for the nonseeded case. For the seeded cases, seeding particles have radii of $0.25 \mu \mathrm{m}$ (red line), $0.5 \mu \mathrm{m}$ (green line), $1 \mu \mathrm{m}$ (blue line), $2.5 \mu \mathrm{m}$ (purple line), or $5 \mu \mathrm{m}$ (orange line). Four total amounts of seeding particles are examined, with ratios of 0.1 (a), $0.5(\mathbf{b}), 1.0(\mathbf{c})$, and $10(\mathbf{d})$. Table 1 presents the number concentrations of seeding particles under the cloud base. For reference, a black broken line in each panel shows accumulated surface rainfall from a non-seeded maritime cloud (the size distribution of the maritime background CCN is shown by the purple line in Fig. 4). A larger amount of seeding particles $0.25 \mu \mathrm{m}$ in radius leads to less surface rainfall. Seeding with particles $0.5 \mu \mathrm{m}$ in radius increases surface rainfall if a sufficient amount of seeding particles is used $\left(250 \mathrm{~cm}^{-3}\right.$, Fig. $\left.7 \mathrm{c}\right)$, but decreases the rainfall if the seeding amount is too large $\left(2500 \mathrm{~cm}^{-3}\right.$, Fig. $\left.7 \mathrm{~d}\right)$. A large amount of large seeding particles hastens the onset of surface rainfall and increases rainfall amount. With appropriate hygroscopic 

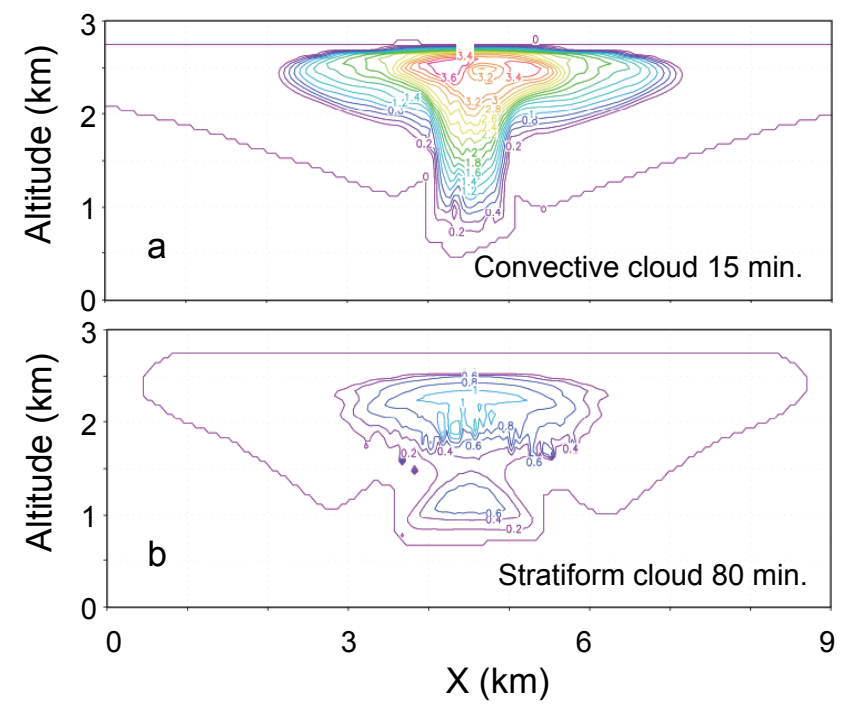

Fig. 5. Cloud water $\left(\mathrm{g} \mathrm{kg}^{-1}\right)$ in the non-seeded case. (a) Convective cloud at $15 \mathrm{~min}$ (10 min after cloud initiation). (b) Stratiform cloud at $80 \mathrm{~min}$ (30 min after cloud initiation).

seeding, the amount of surface rainfall from a moderate continental cloud can become similar to that from a non-seeded maritime cloud. Table 2 shows the ratios of seeded-case to non-seeded-case accumulated rainfall averaged over the domain at $60 \mathrm{~min}$. Ratios representing decrease are given in blue, and those indicating increase are shown in red. Ratios of seeded-case to non-seeded-case $\left(665 \mathrm{~cm}^{-3}\right)$ cloud droplet number concentrations at $50 \mathrm{~m}$ above the base of the cloud center at $11.5 \mathrm{~min}$ are also shown in parentheses in Table 2. These results indicate that seeding can increase rainfall if the size and amount of seeding particles are appropriate to sufficiently decrease the cloud droplet number concentration (cases enclosed by green lines in Table 2). This effect is the competition effect, by which fewer large (here, radii of 0.5 to $2.5 \mu \mathrm{m}$ ) soluble particles prevent the activation of numerous smaller particles. Sufficient numbers of giant particles that can immediately become raindrop embryos (here, larger than $2.5 \mu \mathrm{m}$ ) also increase rainfall (cases enclosed by the orange line in Table 2). This is the raindrop embryo effect. In the seeded case with the largest amount of $2.5-\mu \mathrm{m}$ particles, the rainfall amount increases because of both the competition effect and the raindrop embryo effect. 0.25 - $\mu \mathrm{m}$ particles have neither the competition effect nor the embryo effect because they are not big enough to become raindrop embryo and to compete with the background $\mathrm{CCN}$ for excess water vapor effectively. The optimal radius (written in boldface in Table 2) to increase rainfall becomes larger with the increase in the total mass of seeding particles.

Yin et al. (2000b) investigated the effect of giant CCN on precipitation in convective clouds by numerical study. Because their study included ice-phase, microphysical processes are more complex than our study. However our results
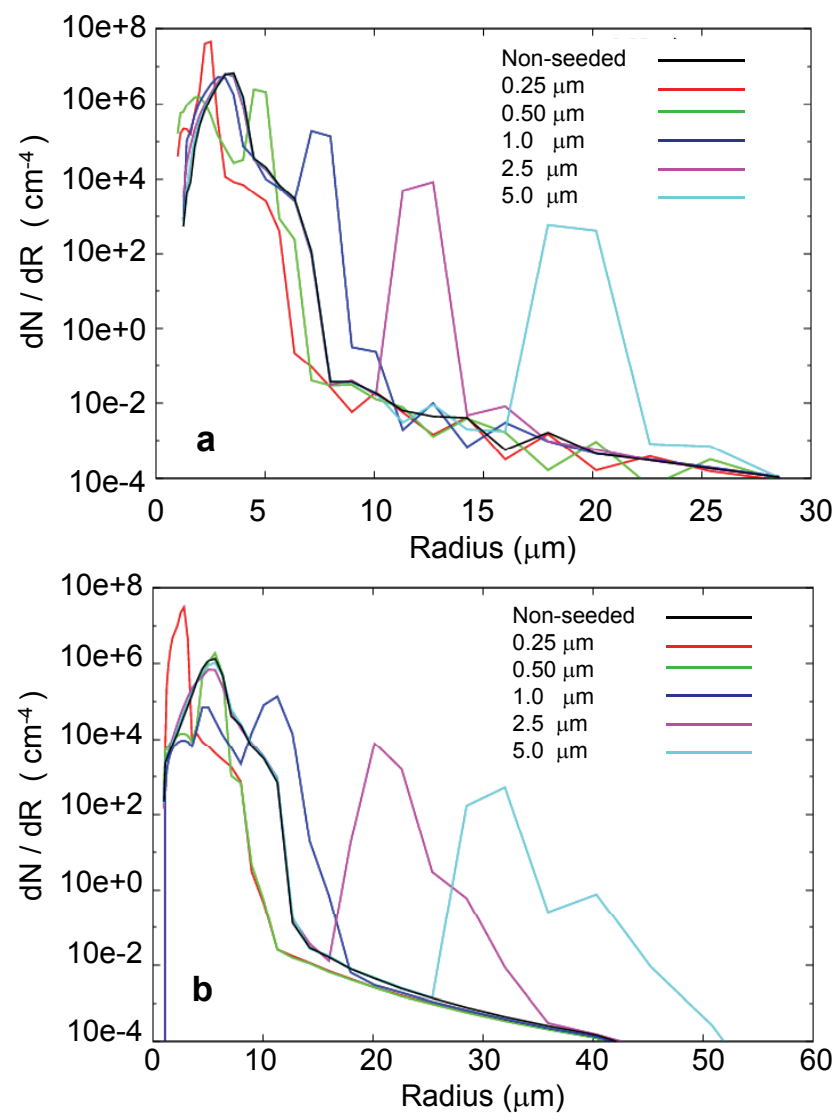

Fig. 6. Cloud droplet size distributions at $100 \mathrm{~m}$ above the base of the cloud center for the shallow convective cloud case (updraft velocity is about $4 \mathrm{~ms}^{-1}$ ) at $11.5 \mathrm{~min}$ (a), and for the stratiform cloud case (updraft velocity is about $0.3 \mathrm{~ms}^{-1}$ ) at $68.5 \mathrm{~min}$ (b). The black line depicts the droplet size distribution for the non-seeded case. For seeded cases, monodisperse salt particles with five different radii are seeded under the cloud base: $0.25 \mu \mathrm{m}$ (red line), $0.5 \mu \mathrm{m}$ (green line), $1.0 \mu \mathrm{m}$ (blue line), $2.5 \mu \mathrm{m}$ (pink line), and $5.0 \mu \mathrm{m}$ (light blue line). For seeding particles of each size, the total mass is the same as the reference total mass ("ratio" $=1$ in Table 1 ).

do not contradict their results. The condition (background $\mathrm{CCN}$, added giant $\mathrm{CCN}$, and updraft velocity) and results of the seeded case with the largest amount of $2.5-\mu \mathrm{m}$ particles in Table 2 is similar to CN1 case in Table 3 in their paper. Comparison of two cases shows that the decrease in cloud droplet number by seeding in our study is larger than their study and the increase in accumulated rainfall averaged over the domain by seeding in our study is smaller than the increase in max. accumulated rain by adding giant $\mathrm{CCN}$ in their study. 
Table 2. Ratios of seeded-case to non-seeded-case accumulated surface rainfall averaged over the domain at 60 min. Seeding of shallow convective cloud is carried out with monodisperse salt particles of different sizes and total masses. Ratios in blue and red indicate a significant decrease and increase, respectively. Ratios of seeded-case to non-seeded case $\left(665 \mathrm{~cm}^{-3}\right)$ cloud droplet number concentrations at $50 \mathrm{~m}$ above the base of the cloud center at $11.5 \mathrm{~min}$ are shown in parentheses.

\begin{tabular}{ccccc}
\hline & \multicolumn{4}{c}{ Ratio of total amount of seeding particles } \\
\cline { 2 - 5 } Radius of seeding particles & 0.1 & 0.5 & 1 & 10 \\
\hline \hline $0.25 \mu \mathrm{m}$ & $1.0(1.09)$ & $0.7(1.66)$ & $0.2(3.13)$ & $0.1(25.2)$ \\
$0.50 \mu \mathrm{m}$ & $1.0(0.97)$ & $1.0(0.87)$ & $1.2(0.56)$ & $0.2(3.38)$ \\
$1.00 \mu \mathrm{m}$ & $1.0(0.99)$ & $1.0(0.94)$ & $1.1(0.88)$ & $1.3(0.37)$ \\
$2.50 \mu \mathrm{m}$ & $1.0(1.00)$ & $1.0(0.98)$ & $1.1(0.97)$ & $1.5(0.37)$ \\
$5.00 \mu \mathrm{m}$ & $1.0(1.00)$ & $1.0(0.99)$ & $1.1(0.99)$ & $1.3(0.85)$ \\
\hline
\end{tabular}
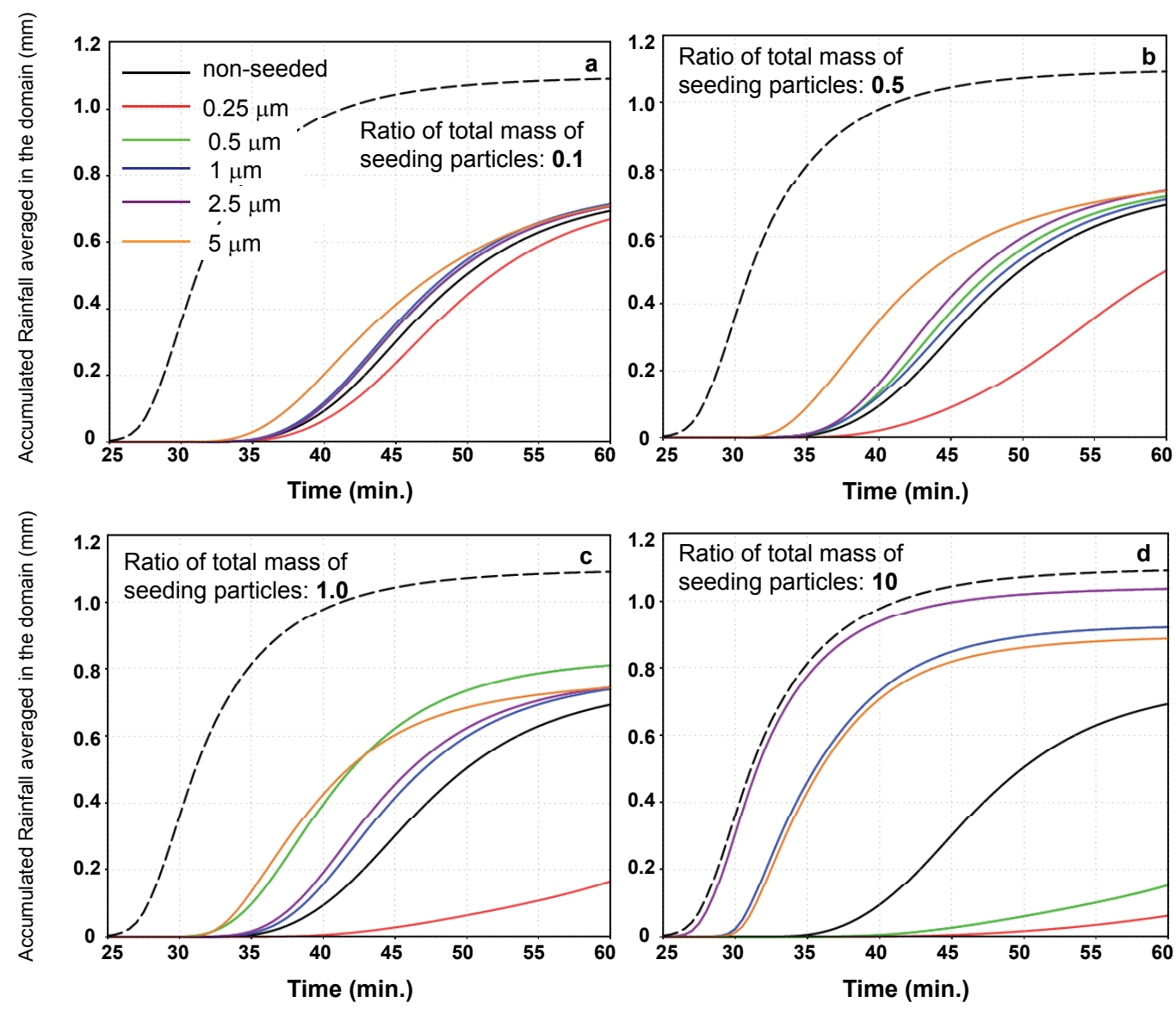

Fig. 7. Temporal change of accumulated surface rainfall averaged over the domain for the shallow convective cloud case. In each panel, the black solid line indicates accumulated surface rainfall for the non-seeded case. For seeded cases, monodisperse salt particles with five different radii are seeded under the cloud base: $0.25 \mu \mathrm{m}$ (red line), $0.5 \mu \mathrm{m}$ (green line), $1 \mu \mathrm{m}$ (blue line), $2.5 \mu \mathrm{m}$ (purple line), and $5 \mu \mathrm{m}$ (orange line). Ratios of the total amounts of seeding particles to the reference are 0.1 (a), 0.5 (b), 1.0 (c), and 10 (d). Number concentrations of seeding particles are shown in Table 1. For reference, accumulated surface rainfall from a non-seeded maritime cloud is also shown in each panel by a black broken line. 
Table 3. Ratios of seeded-case to non-seeded-case accumulated surface rainfall averaged over the domain at 160 min. Seeding of stratiform cloud is carried out with monodisperse salt particles of different sizes and total masses. Ratios in blue and red indicate a significant decrease and increase, respectively. Ratios of seeded-case to non-seeded case $\left(180 \mathrm{~cm}^{-3}\right)$ cloud droplet number concentrations at $100 \mathrm{~m}$ above the base of the cloud center at $62 \mathrm{~min}$ are shown in parentheses.

\begin{tabular}{ccccc}
\hline & \multicolumn{4}{c}{ Ratio of total amount of seeding particles } \\
\cline { 2 - 5 } Radius of seeding particles & \multicolumn{1}{c}{0.1} & 0.5 & 1 & 10 \\
\hline $0.25 \mu \mathrm{m}$ & $1.0(1.16)$ & $0.7(1.95)$ & $0.4(6.08)$ & $0.2(42.3)$ \\
$0.50 \mu \mathrm{m}$ & $1.1(0.80)$ & $1.1(0.94)$ & $1.0(1.13)$ & $0.5(3.28)$ \\
$1.00 \mu \mathrm{m}$ & $1.0(0.84)$ & $1.2(0.69)$ & $1.2(0.72)$ & $1.0(1.17)$ \\
$2.50 \mu \mathrm{m}$ & $1.0(0.93)$ & $1.1(0.72)$ & $1.2(0.55)$ & $1.2(0.48)$ \\
$5.00 \mu \mathrm{m}$ & $1.0(0.97)$ & $1.1(0.79)$ & $1.1(0.63)$ & $1.3(0.42)$ \\
\hline
\end{tabular}
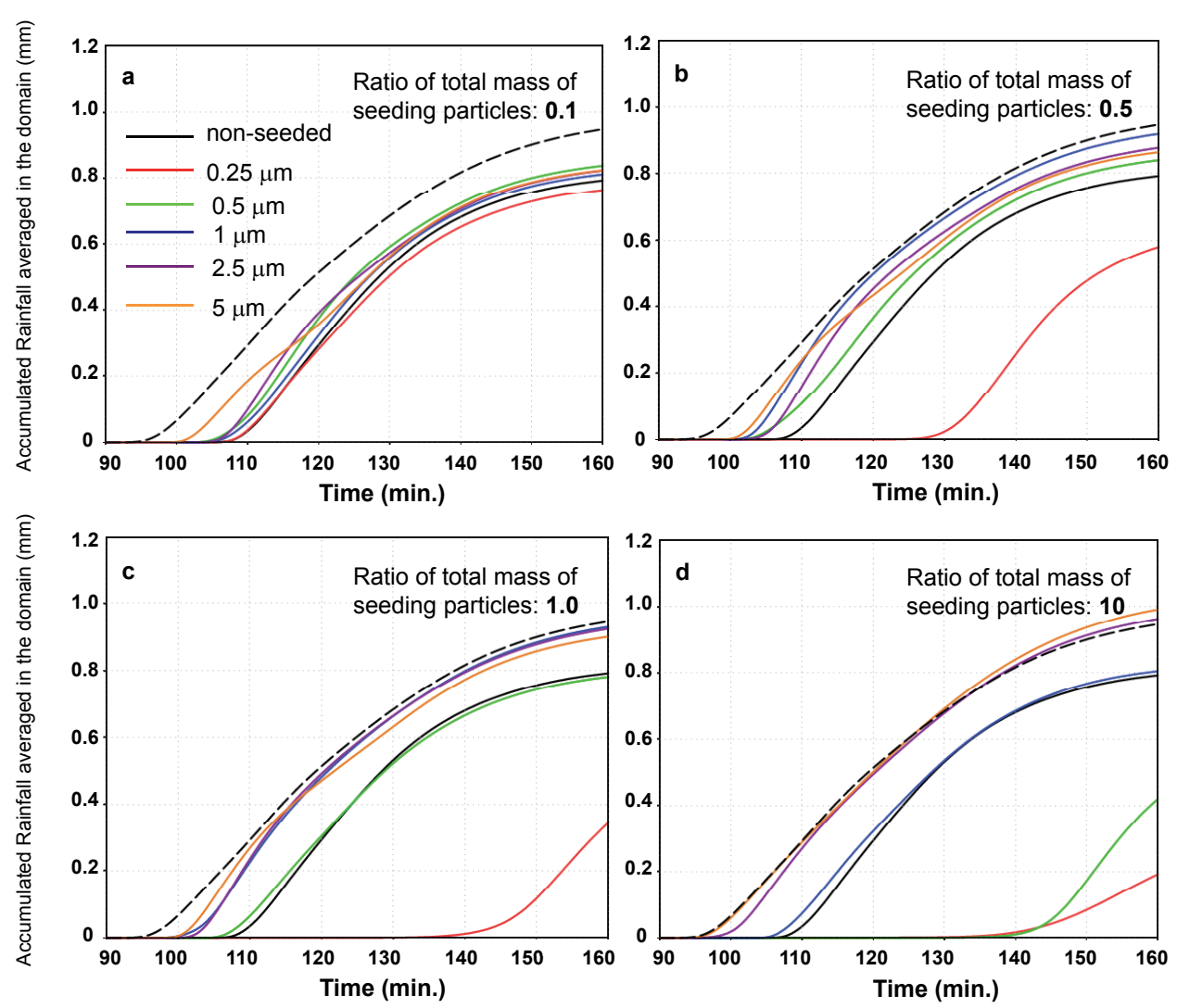

Fig. 8. Same as Fig. 7 except for stratiform cloud.

\subsubsection{Stratiform cloud case}

This section examines the seeding of stratiform cloud (Figs. 2b and $3 b$ ) with monodisperse hygroscopic particles. Figure $6 \mathrm{~b}$ shows the cloud droplet size distribution at $100 \mathrm{~m}$ above the base of the cloud center, as in Fig. 6a; however, in this case the air parcel takes longer to reach $100 \mathrm{~m}$ from the cloud base because of the small updraft velocity. Therefore large droplets, produced by condensational growth of large seeding particles (here, 1.0, 2.5, and $5.0 \mu \mathrm{m}$ in radius) and subsequent coalescence can be seen. Figure 8 shows that a larger amount of $0.25-\mu \mathrm{m}$ radius seeding particles leads to a smaller amount of rainfall. For reference, the accumulated surface rainfall from a non-seeded maritime cloud is also 
Table 4. Ratios of seeded-case to non-seeded case accumulated surface rainfall averaged over the domain at $60 \mathrm{~min}$. Seeding of shallow convective cloud is conducted with salt micro-powder of different concentrations. A ratio indicating increase is colored red. Ratios of seeded-case to non-seeded-case $\left(665 \mathrm{~cm}^{-3}\right)$ cloud droplet number concentrations at $50 \mathrm{~m}$ above the base of the cloud center at $11.5 \mathrm{~min}$ are shown in parentheses.

\begin{tabular}{lcccc}
\hline $\begin{array}{l}\text { Number concentration of } \\
\text { seeding particles }\left(\mathrm{cm}^{-3}\right)\end{array}$ & 9.0 & 45 & 90 & 180 \\
\hline $\begin{array}{l}\text { Total mass of seeding } \\
\text { particles }\left(\mathrm{g} \mathrm{m}^{-3}\right)\end{array}$ & $2 \times 10^{-5}$ & $1 \times 10^{-4}$ & $2 \times 10^{-4}$ & $4 \times 10^{-4}$ \\
\hline $\begin{array}{l}\text { Ratio of accumulated } \\
\text { rainfall to non-seeding case }\end{array}$ & $1.0(0.99)$ & $1.0(0.95)$ & $1.0(0.88)$ & $1.2(0.56)$ \\
\hline
\end{tabular}

shown in each panel by a black broken line. Table 3 gives the ratios of seeded-case to non-seeded-case accumulated rainfall averaged over the domain at $160 \mathrm{~min}$. Ratios of the cloud droplet number concentration at $100 \mathrm{~m}$ above the base of the cloud center at $62 \mathrm{~min}$ for the seeded case to that for the non-seeded case $\left(180 \mathrm{~cm}^{-3}\right)$ are also shown in parentheses in Table 3. The results shown in Fig. 8 and Table 3 are similar to those in Fig. 7 and Table 2. However, we can see that the competition effect of giant $\mathrm{CCN}$ (here, from 1 to $5 \mu \mathrm{m}$ in radius) occurs in more cases (cases enclosed by green lines in Table 3) than in Table 2 because low updraft velocities allow the low number concentrations of activated droplets to grow larger and deplete more excess water vapor, leading to an enhanced competition effect and simultaneously, the raindrop embryo effect to some extent. Note that a decrease in the cloud droplet number concentration does not always lead to a remarkable increase in accumulated surface rainfall. In the cloud with low updraft velocity, the number concentrations of cloud droplets are small enough (cloud droplet sizes are large enough) to produce raindrops effectively even for the non-seeded case. Therefore, the difference in accumulated surface rainfall amount between seeded and non-seeded cases is less than expected from the ratio of cloud droplet number concentrations. $0.25-\mu \mathrm{m}$ particles have neither the competition effect nor the embryo effect even in stratiform cloud case as well as in convective cloud case (Sect. 3.1.1).

\subsection{Hygroscopic seeding with salt micro-powder}

We now investigate seeding with salt micro-powder (Oshiomicron, produced by Ako Kasei, Co., Ako, Japan). These seeding particles are made of $\mathrm{NaCl}$, and their size distribution is approximated by a log-normal distribution. The size distribution of salt micro-powder in this study is assumed to be log-normal with a mode radius of $0.5 \mu \mathrm{m}$ and total concentration of $90 \mathrm{~cm}^{-3}$, as shown by the green line in Fig. 4 . However, salt micro-powder with a mode radius as small as $0.4 \mu \mathrm{m}$ can be manufactured.
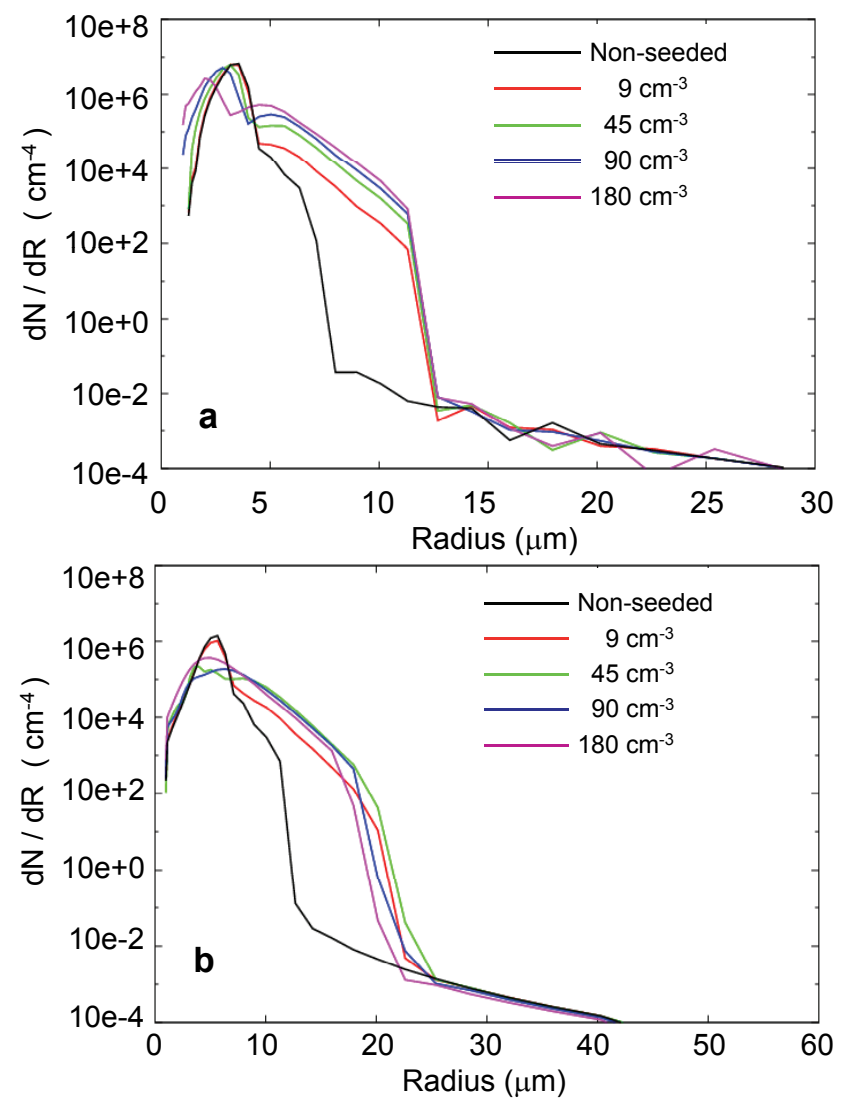

Fig. 9. Cloud droplet size distributions at $100 \mathrm{~m}$ above the base of the cloud center for the shallow convective cloud case (updraft velocity is about $4 \mathrm{~ms}^{-1}$ ) at $11.5 \mathrm{~min}$ (a) and for the stratiform cloud case (updraft velocity is about $0.3 \mathrm{~ms}^{-1}$ ) at $68.5 \mathrm{~min}(\mathbf{b})$. The black line indicates the droplet size distribution for the non-seeded case. For seeded cases, different total number concentrations of salt micro-powder are seeded under the cloud base: $9 \mathrm{~cm}^{-3}$ (red line), $45 \mathrm{~cm}^{-3}$ (green line), $90 \mathrm{~cm}^{-3}$ (blue line), or $180 \mathrm{~cm}^{-3}$ (purple line).

\subsubsection{Shallow convective cloud case}

For this simulation, we seed a shallow convective cloud with the salt micro-powder. Figure 9a shows the cloud droplet size distributions at $100 \mathrm{~m}$ above the base of the cloud center (updraft velocity is about $4 \mathrm{~ms}^{-1}$ ) at $11.5 \mathrm{~min}(90 \mathrm{~s}$ after the start of seeding) for the non-seeded case (black line) and seeded cases. For the seeded cases, number concentrations of salt micro-powder under the cloud base are $9 \mathrm{~cm}^{-3}$ (red line), $45 \mathrm{~cm}^{-3}$ (green line), $90 \mathrm{~cm}^{-3}$ (blue line), and $180 \mathrm{~cm}^{-3}$ (purple line). The cloud droplets condensed on the salt micro-powder range from approximately 5 to $12 \mu \mathrm{m}$ in radius, and a larger amount of seeding particles decreases the mode radius and number of droplets condensed on background CCN. 

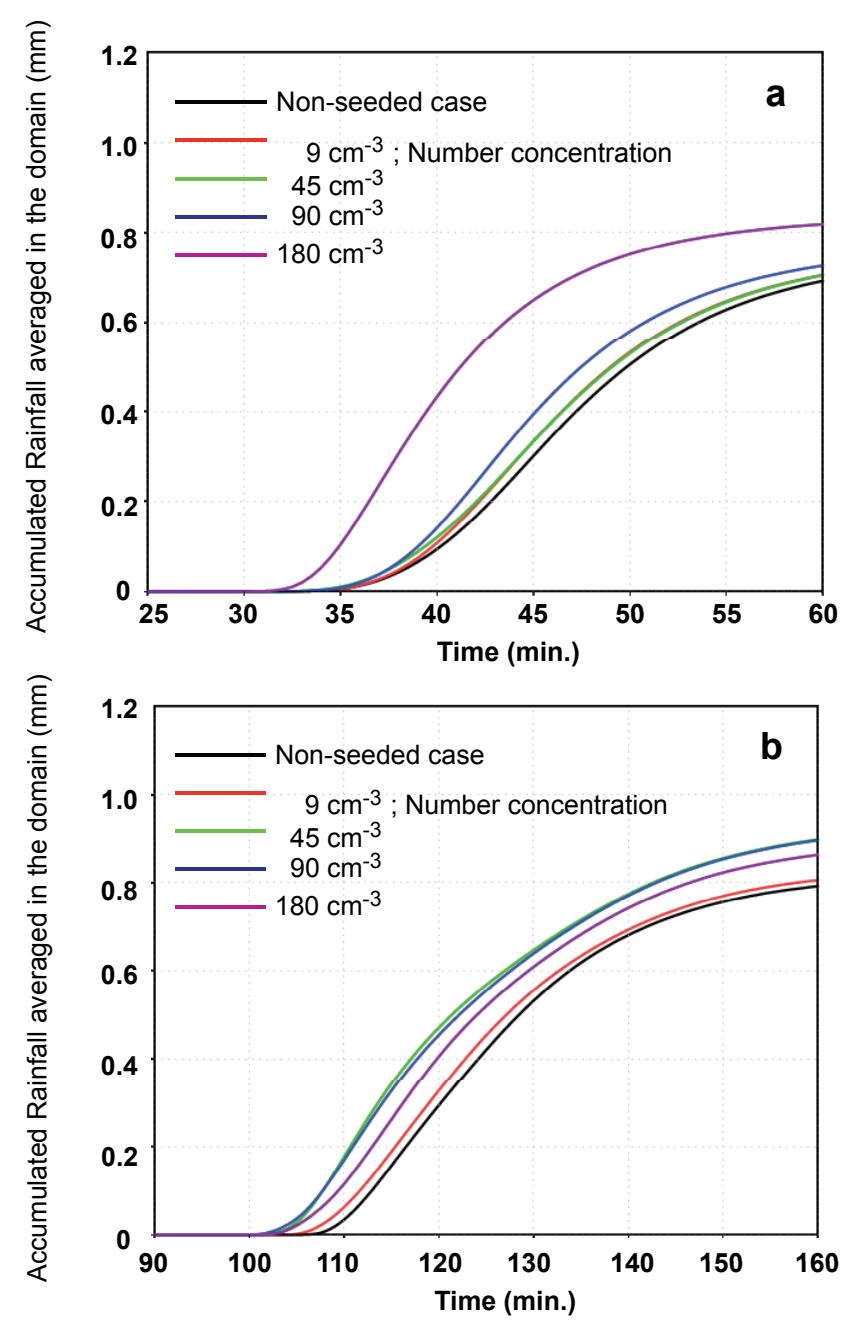

Fig. 10. Temporal change in accumulated surface rainfall averaged over the domain for the shallow convective cloud case (a) and stratiform cloud case (b). The black line indicates accumulated surface rainfall for the non-seeded case. For seeded cases, different total number concentrations of salt micro-powder are seeded under the cloud base: $9 \mathrm{~cm}^{-3}$ (red line), $45 \mathrm{~cm}^{-3}$ (green line), $90 \mathrm{~cm}^{-3}$ (blue line), or $180 \mathrm{~cm}^{-3}$ (purple line).

Figure 10a shows temporal change in accumulated rainfall averaged over the domain, and Table 4 gives the ratios of accumulated rainfall averaged over the domain at $60 \mathrm{~min}$ for the seeded case to that for the non-seeded case. Figure 10a and Table 4 show that seeding with salt micro-powder hastens the onset of surface rainfall and increases accumulated rainfall due to the competition effect if there is a sufficient number of seeding particles. The results shown in Table 4 are similar to those for seeding particles with a radius of $0.5 \mu \mathrm{m}$ in Table 2.
Table 5. Ratios of seeded-case to non-seeded-case accumulated surface rainfall averaged over the domain at $160 \mathrm{~min}$. Seeding of stratiform cloud is carried out with salt micro-powder of different concentrations. Ratios of seeded-case to non-seeded-case $\left(180 \mathrm{~cm}^{-3}\right)$ cloud droplet number concentrations at $100 \mathrm{~m}$ above the base of the cloud center at $62 \mathrm{~min}$ are shown in parentheses.

\begin{tabular}{lcccc}
\hline $\begin{array}{l}\text { Number concentration of } \\
\text { seeding particles }\left(\mathrm{cm}^{-3}\right)\end{array}$ & 9.0 & 45 & 90 & 180 \\
\hline $\begin{array}{l}\text { Total mass of seeding } \\
\text { particles }\left(\mathrm{g} \mathrm{m}^{-3}\right)\end{array}$ & $2 \times 10^{-5}$ & $1 \times 10^{-4}$ & $2 \times 10^{-4}$ & $4 \times 10^{-4}$ \\
\hline $\begin{array}{l}\text { Ratio of accumulated } \\
\text { rainfall to non-seeding case }\end{array}$ & $1.0(0.85)$ & $1.1(0.84)$ & $1.1(0.76)$ & $1.1(0.81)$ \\
\hline
\end{tabular}

\subsubsection{Stratiform cloud case}

Seeding the stratiform cloud with salt micro-powder is carried out from under the cloud base. Figure $9 \mathrm{~b}$ shows the cloud droplet size distributions at $100 \mathrm{~m}$ above the base of the cloud center (updraft velocity is approximately $0.3 \mathrm{~ms}^{-1}$ ) at $68.5 \mathrm{~min}$ ( $13.5 \mathrm{~min}$ after the start of seeding) for the non-seeded case and seeded cases. The radii of cloud droplets condensed on salt micro-powder range from about 8 to $22 \mu \mathrm{m}$. Table 5 lists accumulated rainfall averaged over the domain at $160 \mathrm{~min}$. Figure $10 \mathrm{~b}$ and Table 5 show that seeding with micro-powder can hasten the onset of surface rainfall and increase the accumulated amount of surface rainfall from stratiform cloud, but its effect is smaller than that in the shallow convective cloud case (Fig. 10a and Table 4). Seeding with salt micro-powder can decrease the number concentrations of cloud droplets to some extent. However, in the stratiform cloud with low updraft velocity, cloud droplet number concentrations are small enough (cloud droplet sizes are sufficiently large) to produce raindrops effectively even for the non-seeded case. Therefore, the differences in the accumulated surface rainfall amount between seeded and nonseeded cases are less remarkable than for the shallow convective cloud in which the non-seeded case did not efficiently produce raindrops.

\subsection{Hygroscopic seeding by a flare}

Field and numerical experiments have examined several kinds of flares. The blue line in Fig. 4 shows the size distribution of seeding particles composed of $\mathrm{CaCl}_{2}$ produced from a burning flare based on laboratory measurements for the "ICE 70\% flare" produced by Ice Crystal Engineering (R. T. Bruintjes, personal communication, 2006). The size distribution without particles larger than $5 \mu \mathrm{m}$ in radius is also examined to estimate the effect of hygroscopic seeding particles with large radius but low number concentration. This size distribution has a total number concentration of hygroscopic particles of $970 \mathrm{~cm}^{-3}$. Here, we examine three 

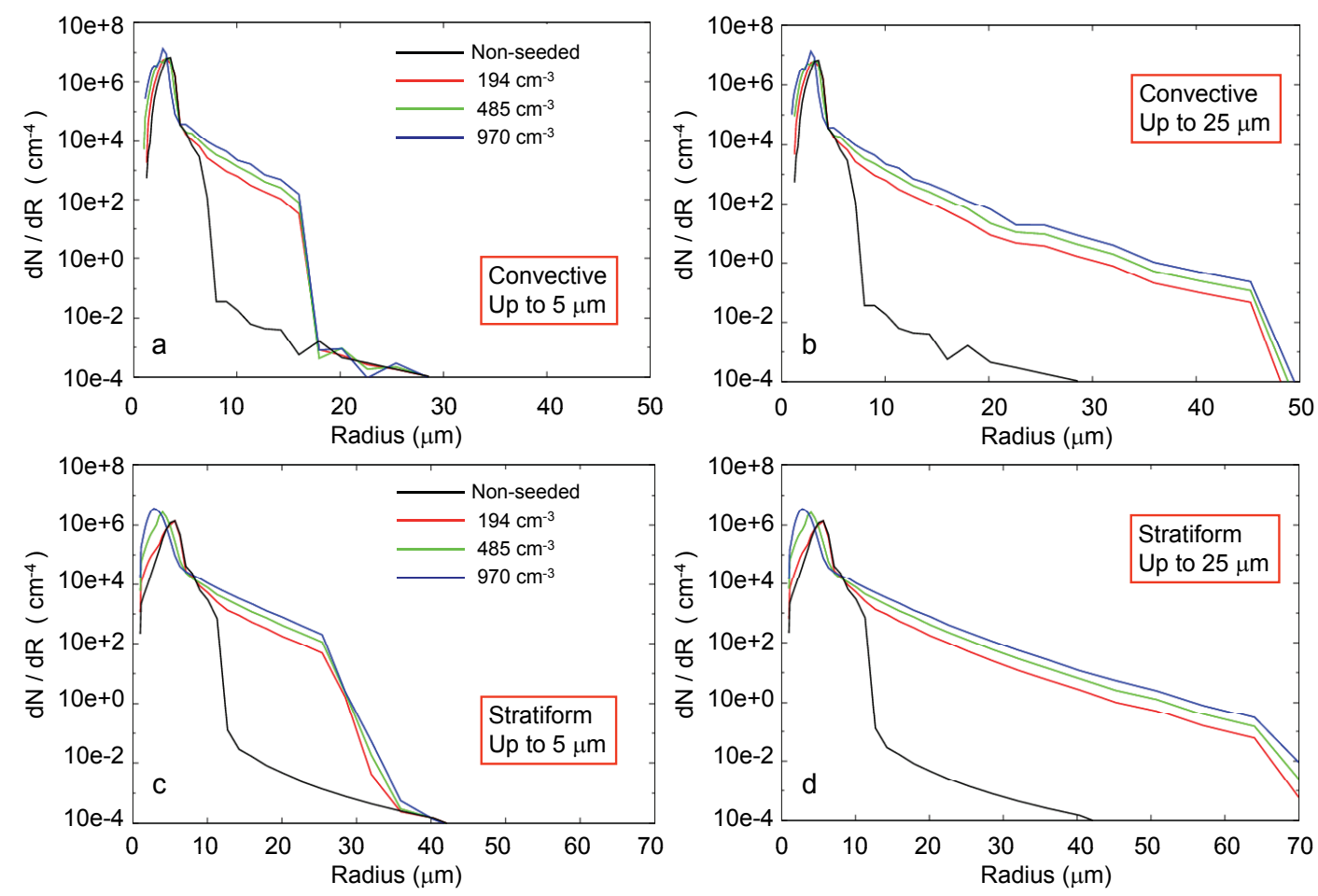

Fig. 11. Cloud droplet size distributions at $100 \mathrm{~m}$ above the base of the cloud center for the shallow convective cloud case (updraft velocity is about $4 \mathrm{~ms}^{-1}$ ) at $11.5 \mathrm{~min}$ (a) and (b) and for the stratiform cloud case (updraft velocity is about $0.3 \mathrm{~ms}^{-1}$ ) at $68.5 \mathrm{~min}$ (c) and (d). Numerical simulations are performed with flare particles with radii up to $5 \mu \mathrm{m}$ (a) and (c) or up to $25 \mu \mathrm{m}$ (b) and (d). The black line indicates the size distribution for the non-seeded case. For seeded cases, different total number concentrations of flare particles are seeded under the cloud base: $194 \mathrm{~cm}^{-3}$ (red line), $485 \mathrm{~cm}^{-3}$ (green line), and $970 \mathrm{~cm}^{-3}$ (blue line).

number concentrations of particles seeded under the cloud base $\left(194 \mathrm{~cm}^{-3}, 485 \mathrm{~cm}^{-3}\right.$, and $\left.970 \mathrm{~cm}^{-3}\right)$.

\subsubsection{Shallow convective cloud case}

The shallow convective cloud is seeded with flare particles with radii up to $5 \mu \mathrm{m}$ or up to $25 \mu \mathrm{m}$. Figure $11 \mathrm{a}$ and $\mathrm{b}$ show the cloud droplet size distributions at $100 \mathrm{~m}$ above the base of the cloud center (updraft velocity is approximately $4 \mathrm{~ms}^{-1}$ ) at $11.5 \mathrm{~min}(90 \mathrm{~s}$ after the start of seeding) for the non-seeded and seeded cases. The black line indicates the droplet size distribution for the non-seeded case. For seeded cases, hygroscopic flare particles with number concentrations of $194 \mathrm{~cm}^{-3}$ (red line), $485 \mathrm{~cm}^{-3}$ (green line), and $970 \mathrm{~cm}^{-3}$ (blue line) are seeded under the cloud base. The cloud droplets condensed on the seeding particles range from approximately 5 to $18 \mu \mathrm{m}$ (Fig. 11a) or 5 to $46 \mu \mathrm{m}$ (Fig. 11b) in radius. Furthermore, with larger amounts of seeding particles, the mode radius of droplets decreases, and the cloud droplet number increases.

Figure 12 shows the temporal change of accumulated rainfall averaged over the domain. Tables 6 and 7 give ratios of seeded-case to non-seeded-case accumulated rainfall averaged over the domain at 40 and $60 \mathrm{~min}$. The results in
Fig. 12a and Table 6 indicate that seeding with flare particles up to $5 \mu \mathrm{m}$ in radius increases cloud droplet number concentrations and decreases surface rainfall. The numerous small particles produced from a burning flare suppress the condensational growth of cloud droplets, decrease the collisioncoalescence efficiency of cloud droplets, and consequently decrease surface rainfall. The effect of small seeding particles' increasing the number of activated cloud droplets is dominant over the competition effect of large seeding particles' (larger than $0.5 \mu \mathrm{m}$ in radius, in convective cloud cases) suppressing the activation of smaller CCN.

Figure 12b and Table 7 show that seeding with flare particles up to $25 \mu \mathrm{m}$ in radius also increases cloud droplet number concentrations but hastens the onset of surface rainfall and increases the accumulated amount of surface rainfall due to the raindrop embryo effect of giant and ultra-giant $\mathrm{CCN}$ (larger than $5 \mu \mathrm{m}$ in radius, in convective cloud cases) at $40 \mathrm{~min}$. However, it slightly decreases the accumulated amount of surface rainfall at $60 \mathrm{~min}$. This indicates that during the early stage of rain formation, raindrop embryos originating from CCN larger than $5 \mu \mathrm{m}$ in radius efficiently collect cloud droplets and promote raindrop formation. However, during the late stage of rain formation, when most of the raindrop embryos originating from $\mathrm{CCN}$ larger than $5 \mu \mathrm{m}$ 
Table 6. Ratios of seeded-case to non-seeded-case accumulated surface rainfall averaged over the domain at 40 and $60 \mathrm{~min}$. Seeding of shallow convective cloud is carried out with flare particles (up to $5 \mu \mathrm{m}$ in radius). A ratio indicating a decrease is colored blue. Ratios of seeded-case to non-seeded-case $\left(665 \mathrm{~cm}^{-3}\right)$ cloud droplet number concentrations at $50 \mathrm{~m}$ above the base of the cloud center at $11.5 \mathrm{~min}$ are shown in parentheses.

\begin{tabular}{lccc}
\hline $\begin{array}{l}\text { Number concentration of } \\
\text { Seeding particles }\left(\mathrm{cm}^{-3}\right)\end{array}$ & 194 & 485 & 970 \\
\hline $\begin{array}{l}\text { Total mass of seeding } \\
\text { particles }\left(\mathrm{g} \mathrm{m}^{-3}\right)\end{array}$ & $4.7 \times 10^{-5}$ & $1.2 \times 10^{-4}$ & $2.4 \times 10^{-4}$ \\
\hline $\begin{array}{l}\text { Ratio of accumulated rainfall to } \\
\text { non-seeding case at } 40 \text { min. }\end{array}$ & 0.8 & 0.5 & 0.3 \\
\hline $\begin{array}{l}\text { Ratio of accumulated rainfall to } \\
\text { non-seeding case at } 60 \text { min. }\end{array}$ & $1.0(1.14)$ & $0.9(1.34)$ & $0.8(1.67)$ \\
\hline
\end{tabular}

Table 7. Ratios of seeded-case to non-seeded-case accumulated surface rainfall averaged over the domain at 40 and $60 \mathrm{~min}$. Seeding of shallow convective cloud is carried out with flare particles (up to $25 \mu \mathrm{m}$ in radius). A ratio indicating an increase is colored red. Ratios of seeded-case to non-seeded-case $\left(665 \mathrm{~cm}^{-3}\right)$ cloud droplet number concentrations at $50 \mathrm{~m}$ above the base of the cloud center at $11.5 \mathrm{~min}$ are shown in parentheses.

\begin{tabular}{lccc}
\hline $\begin{array}{l}\text { Number concentration of } \\
\text { Seeding particles }\left(\mathrm{cm}^{-3}\right)\end{array}$ & 194 & 485 & 970 \\
\hline $\begin{array}{l}\text { Total mass of seeding } \\
\text { particles }\left(\mathrm{g} \mathrm{m}^{-3}\right)\end{array}$ & $9.4 \times 10^{-5}$ & $2.4 \times 10^{-4}$ & $4.7 \times 10^{-4}$ \\
\hline $\begin{array}{l}\text { Ratio of accumulated rainfall to } \\
\text { non-seeding case at } 40 \text { min. }\end{array}$ & 1.7 & 2.1 & 2.1 \\
\hline $\begin{array}{l}\text { Ratio of accumulated rainfall to } \\
\text { non-seeding case at } 60 \text { min. }\end{array}$ & $1.0(1.14)$ & $0.9(1.33)$ & $0.9(1.66)$ \\
\hline
\end{tabular}

have grown into raindrops and fallen out of the cloud as precipitation, numerous cloud droplets with smaller sizes are left in the cloud without efficiently producing raindrops.

\subsubsection{Stratiform cloud case}

Next, seeding of a stratiform cloud with flare particles up to $5 \mu \mathrm{m}$ or up to $25 \mu \mathrm{m}$ in radius is simulated. Figure $11 \mathrm{c}$ and d show the cloud droplet size distributions at $100 \mathrm{~m}$ above the base of the cloud center (updraft velocity is approximately $\left.0.3 \mathrm{~ms}^{-1}\right)$ at $68.5 \mathrm{~min}(13.5 \mathrm{~min}$ after the start of seeding) for the non-seeded and seeded cases. As illustrated in these figures, cloud droplets condensed on seeding particles range from 8 to $35 \mu \mathrm{m}$ (Fig. 11c) or from 8 to $65 \mu \mathrm{m}$ (Fig. 11d) in radius, and larger amounts of seeding particles lead to smaller mode radii of droplets and increased cloud droplet numbers.

Figure 13 shows the seeding effect on accumulated surface rainfall for hygroscopic flare particles up to $5 \mu \mathrm{m}$ (a) and $25 \mu \mathrm{m}$ (b) in radius. Tables 8 and 9 present ratios of seededcase to non-seeded-case accumulated rainfall averaged over

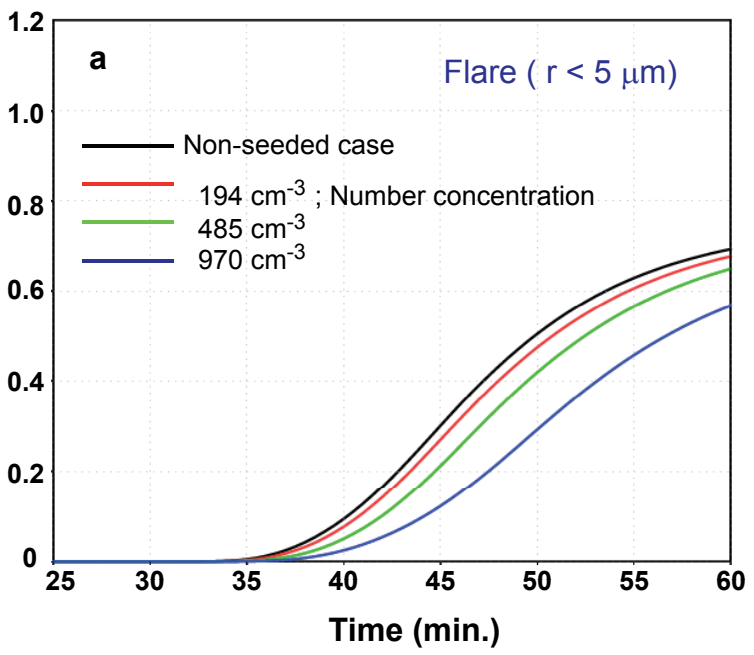

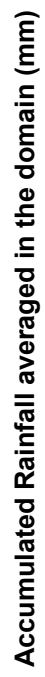

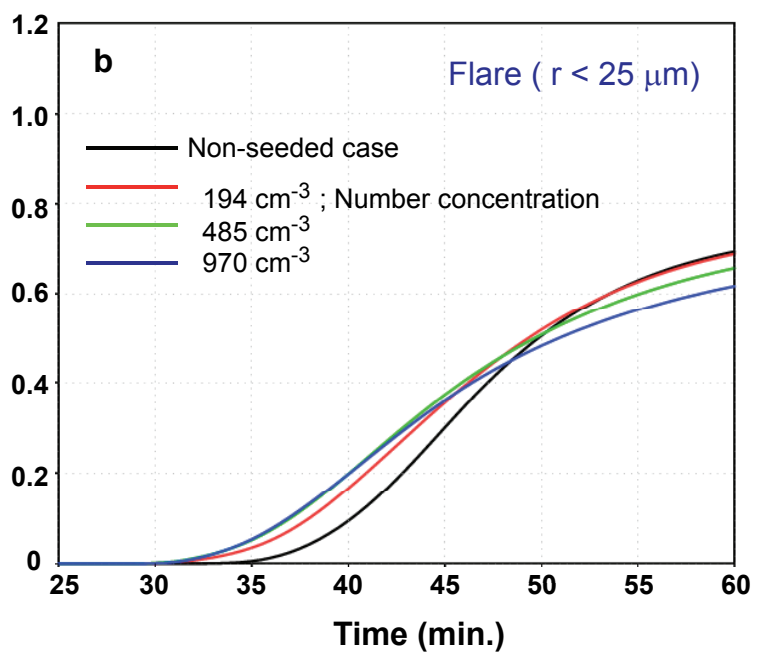

Fig. 12. Temporal change of accumulated surface rainfall averaged over the domain. Shallow convective cloud is seeded with flare particles up to $5 \mu \mathrm{m}$ (a) or up to $25 \mu \mathrm{m}$ (b) in radius. The black line indicates the accumulated surface rainfall for the non-seeded case. For seeded cases, different total number concentrations of flare particles are seeded under the cloud base: $194 \mathrm{~cm}^{-3}$ (red line), $485 \mathrm{~cm}^{-3}$ (green line), or $970 \mathrm{~cm}^{-3}$ (blue line).

the domain at 120 and 160 min. Figure 13 and Tables 8 and 9 show that seeding with flare particles up to $5 \mu \mathrm{m}$ or $25 \mu \mathrm{m}$ increases the cloud droplet number, hastens the onset of surface rainfall, and increases accumulated surface rainfall for the first $120 \mathrm{~min}$, as in the convective cloud cases (Fig. 12 and Tables 6 and 7). However, unlike the convective cloud cases, it does not decrease the accumulated amount of rainfall at $160 \mathrm{~min}$.

Table 8 and Fig. 13a show that appropriate concentrations of large and giant CCN (smaller than $5 \mu \mathrm{m}$ ) produce large cloud droplets, but not numerous small droplets, and 
Table 8. Ratios of seeded-case to non-seeded-case accumulated surface rainfall averaged over the domain at 120 and $160 \mathrm{~min}$. Seeding of stratiform cloud is carried out with flare particles (up to $5 \mu \mathrm{m}$ in radius). A ratio indicating an increase is colored red. Ratios of seeded-case to non-seeded-case $\left(180 \mathrm{~cm}^{-3}\right)$ cloud droplet number concentrations at $100 \mathrm{~m}$ above the base of the cloud center at $62 \mathrm{~min}$ are shown in parentheses.

\begin{tabular}{lccc}
\hline $\begin{array}{l}\text { Number concentration of } \\
\text { Seeding particles }\left(\mathrm{cm}^{-3}\right)\end{array}$ & 194 & 485 & 970 \\
\hline $\begin{array}{l}\text { Total mass of seeding } \\
\text { particles }\left(\mathrm{g} \mathrm{m}^{-3}\right)\end{array}$ & $4.7 \times 10^{-5}$ & $1.2 \times 10^{-4}$ & $2.4 \times 10^{-4}$ \\
\hline $\begin{array}{l}\text { Ratio of accumulated rainfall to } \\
\text { non-seeding case at } 120 \text { min. }\end{array}$ & 1.3 & 1.2 & 1.1 \\
\hline $\begin{array}{l}\text { Ratio of accumulated rainfall to } \\
\text { non-seeding case at } 160 \text { min. }\end{array}$ & $1.0(0.99)$ & $1.0(0.98)$ & $1.0(1.37)$ \\
\hline
\end{tabular}

Table 9. Ratios of seeded-case to non-seeded-case accumulated surface rainfall averaged over the domain at 120 and $160 \mathrm{~min}$. Seeding of stratiform cloud is carried out with flare particles (up to $25 \mu \mathrm{m}$ in radius). A ratio indicating an increase is colored red. Ratios of seeded-case to non-seeded-case $\left(180 \mathrm{~cm}^{-3}\right)$ cloud droplet number concentrations at $100 \mathrm{~m}$ above the base of the cloud center at $62 \mathrm{~min}$ are shown in parentheses.

\begin{tabular}{lccc}
\hline $\begin{array}{l}\text { Number concentration of } \\
\text { Seeding particles }\left(\mathrm{cm}^{-3}\right)\end{array}$ & 194 & 485 & 970 \\
\hline $\begin{array}{l}\text { Total mass of seeding } \\
\text { particles }\left(\mathrm{g} \mathrm{m}^{-3}\right)\end{array}$ & $9.4 \times 10^{-5}$ & $2.4 \times 10^{-4}$ & $4.7 \times 10^{-4}$ \\
\hline $\begin{array}{l}\text { Ratio of accumulated rainfall to } \\
\text { non-seeding case at 120 min. }\end{array}$ & 1.3 & 1.4 & 1.4 \\
\hline $\begin{array}{l}\text { Ratio of accumulated rainfall to } \\
\text { non-seeding case at } 160 \text { min. }\end{array}$ & $1.0(0.97)$ & $1.1(0.94)$ & $1.0(1.26)$ \\
\hline
\end{tabular}

enhance the collision-calescence process, resulting in not only a slightly early onset of rainfall but also a slight increase in accumulated surface rainfall even at $160 \mathrm{~min}$. However, high concentrations of large and giant $\mathrm{CCN}$ increase the number concentrations of cloud droplets and decrease their sizes, suppressing the collision-coalescence process and raindrop formation.

On the other hand, as seen in Table 9 and Fig. 13b, giant and ultra-giant $\mathrm{CCN}$ (up to $25 \mu \mathrm{m}$ ) produce raindrop embryos, hastening the onset of rainfall and slightly increasing the accumulated amount of surface rainfall even at $160 \mathrm{~min}$. The enhancement of raindrop formation due to higher concentrations of raindrop embryos is dominant over the suppression of raindrop formation due to numerous small droplets.
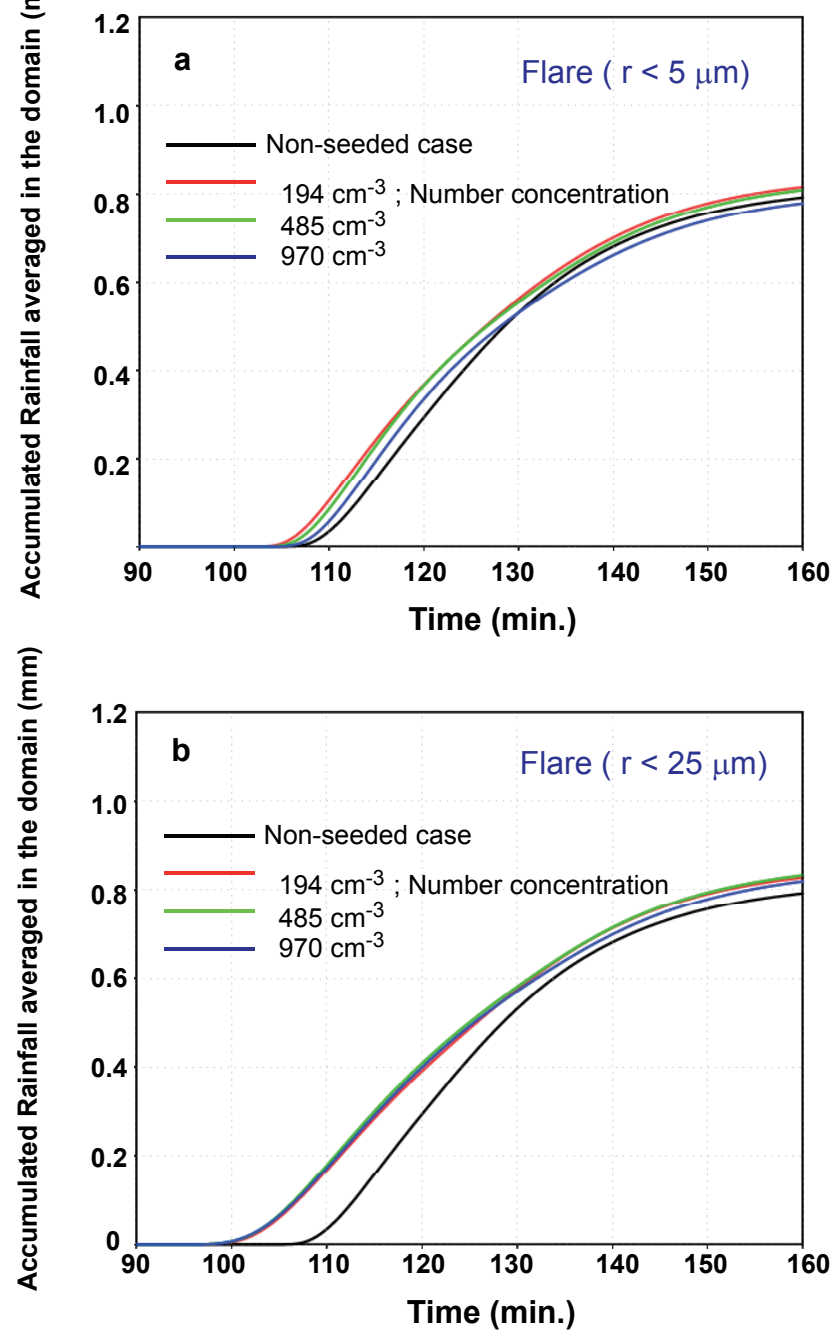

Fig. 13. Same as Fig. 12 except for stratiform cloud.

\section{Conclusions}

This study examined the effects of hygroscopic seeding on shallow warm rain clouds using a hybrid cloud microphysical model combining Lagrangian, semi-Lagrangian, and Eulerian frameworks. The hybrid cloud microphysical model can accurately estimate the effect of $\mathrm{CCN}$ on cloud microstructure. The simulation results suggest the following conclusions regarding moderate continental air masses.

1. Seeding can hasten the onset of surface rainfall and increase the accumulated amount of surface rainfall if the radius and amount of seeding particles are appropriate.

2. The optimal radius to increase rainfall becomes larger with the increase in total amount of seeding particles.

3. Seeding with salt micro-powder can hasten the onset of surface rainfall and increase the accumulated amount 

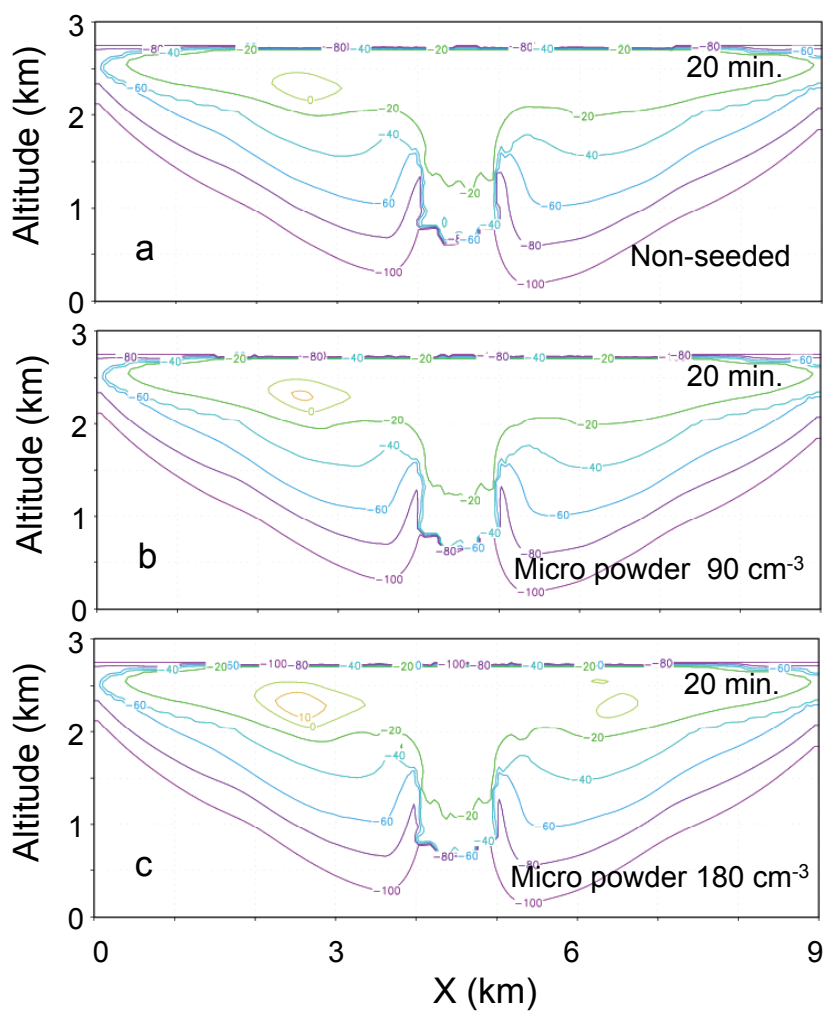

Fig. 14. Radar reflectivity in shallow convective cloud at $20 \mathrm{~min}$ for the non-seeded case (a) and for seeded cases with salt micropowder of different total number concentrations: $90 \mathrm{~cm}^{-3}$ (b) and $180 \mathrm{~cm}^{-3}$ (c).

of surface rainfall if the amount of seeding particles is sufficient (about $4 \mathrm{e}-4 \mathrm{~g} \mathrm{~m}^{-3}$ ) and the updraft velocity is large (shallow convective cloud).

4. Seeding with a hygroscopic flare decreases rainfall in the case of large updraft velocity (shallow convective cloud) and slightly increases rainfall in the case of small updraft velocity (stratiform cloud).

5. Seeding with flare particles including ultra-giant particles $(r>5 \mu \mathrm{m})$ hastens the onset of surface rainfall.

6. Two effects of hygroscopic seeding increase surface rainfall: the "competition effect", whereby large soluble particles prevent the activation of numerous smaller particles, and the "raindrop embryo effect" of giant and ultra-giant soluble particles that can immediately become raindrop embryos. In some cases, one of the effects works, and in other cases, both effects work, depending on the updraft velocity and the amount and size of seeding particles.

Our results from hygroscopic flare seeding (4 and 5) do not contradict the results of Cooper et al. (1997) and Caro et al. (2002). Their results showed that the addition of hygroscopic particles can significantly accelerate rain formation through the warm-rain process. They used parcel models to simulate the seeding effect of a hygroscopic flare's producing a wide range of particle sizes including giant and ultra-giant $\mathrm{CCN}$. They derived their conclusions from cloud droplet size distributions in parcels. Our results also show that seeding with flare particles can affect the cloud droplet size distribution and can hasten the onset of surface rainfall. However, our results derived from the two-dimensional cloud model indicate that accumulated surface rainfall does not increase considerably by hygroscopic flare seeding because of the large number of small particles produced from the burning flare. Generally speaking, parcel models cannot properly express early sedimentation of raindrops and the collection of cloud droplets by raindrops. This issue may explain why our results and those of previous numerical studies using parcel models differ regarding the effectiveness of hygroscopic flare seeding for augmenting accumulated surface precipitation.

Bowen (1950) and Feingold et al. (1996) emphasized the importance of in-cloud dwell time (in-cloud residence time) for drizzle production. Their studies suggest that optimal radius to increase rainfall depends on updraft velocity because larger droplet in weaker updraft leads to smaller residence time. Comparison between Tables 2 and 3 cannot show clear influence of residence time because these tables show only accumulated and averaged surface rainfall. Detail analysis (grid to grid, time to time) is needed to mention the importance of in-cloud dwell time.

Radar-estimated rainfall is often used to assess the effect of hygroscopic seeding in field experiments (e.g., Mather et al., 1997). Figures 14 to 17 show radar reflectivity in shallow convective cloud at 20 and $30 \mathrm{~min}$. These figures indicate that seeding with micro-powder and flare particles increases radar reflectivity. However, in our numerical results, hygroscopic flare seeding decreases rainfall in the case of shallow convective cloud. Therefore, an increase in radar reflectivity does not necessarily mean an increase in the accumulated surface rainfall amount.

Our results suggest, as do others (Kuba and Takeda, 1983; Cooper et al., 1997; Feingold et al., 1999; Saleeby and Cotton, 2004), that the effects of hygroscopic seeding can vary with the background CCN number concentrations (not shown in this paper) and updraft velocity at the cloud base (or cloud types) as well as the sizes and amounts of seeding particles and the timing of seeding (not shown in this paper). Therefore, more observational data must be collected on background $\mathrm{CCN}$ number concentrations and cloud-base updraft velocities.

In this study, the chemical composition of the background $\mathrm{CCN}$ is assumed to be $\mathrm{NaCl}$. We also performed experiments with $\mathrm{CCN}$ composed of $\left(\mathrm{NH}_{4}\right)_{2} \mathrm{SO}_{4}$. The numerical results showed that the hygroscopicity weakens when the chemical composition of $\mathrm{CCN}$ is changed from $\mathrm{NaCl}$ to $\left(\mathrm{NH}_{4}\right)_{2} \mathrm{SO}_{4}$, which decreases the number concentration of activated droplets and consequently increases the 

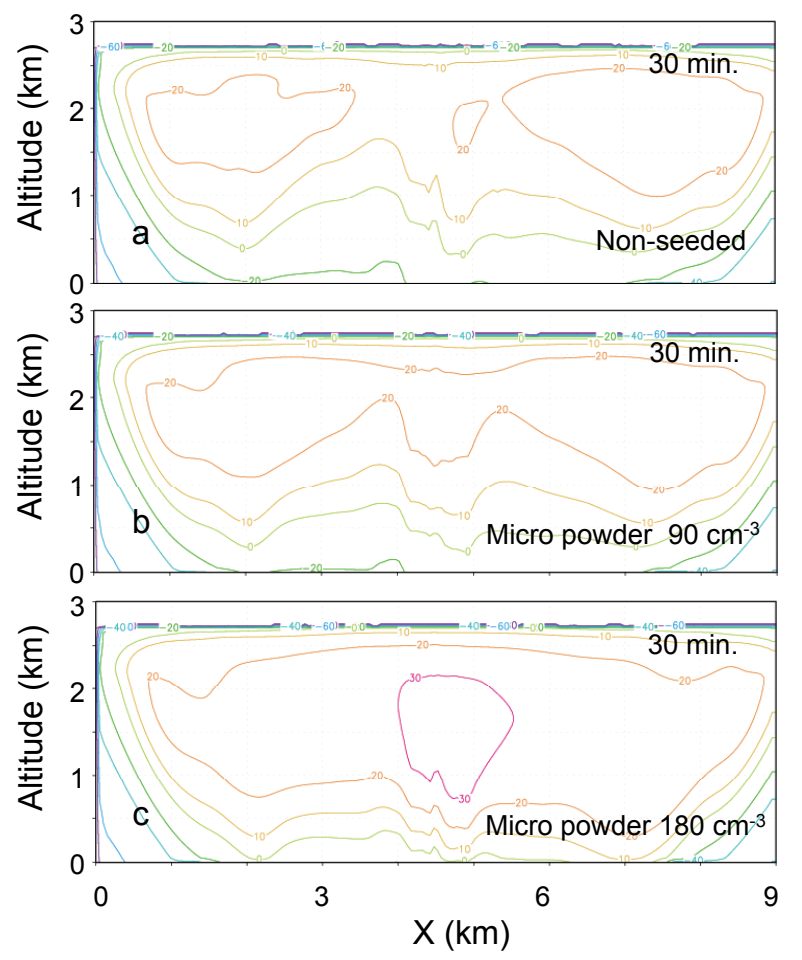

Fig. 15. Same as Fig. 14 except at $30 \mathrm{~min}$.

accumulated surface precipitation. Hygroscopic flare seeding leads to a less positive effect in the early stage and a more negative effect in the late stage. However, our conclusions would not change qualitatively even if we assumed sulfate as the background CCN. Natural variability in atmospheric aerosol size distributions (aerosol sizes and number concentrations) has a larger effect than the difference in chemical composition, as shown by Takeda and Kuba (1982). In the future, we would like to evaluate the seeding effect by numerical simulations using aerosol size distributions (or $\mathrm{CCN}$ activation spectra) observed in the target area.

In this paper, our hybrid cloud microphysical model was used in a kinematic flow field that did not allow dynamical feedbacks associated with entrainment, subcloud evaporation, and cold pools, which impact the potential response of clouds to varying $\mathrm{CCN}$. These effects will be studied by installing our hybrid cloud microphysical model in a nonhydrostatic cloud model in the future.

\section{Appendix A}

\section{Mathematical method for estimating the coalescence process}

In the situations where one cloud droplet collects more than one droplet at a single time step, it is difficult to evaluate the evolution of the droplet size distribution through the
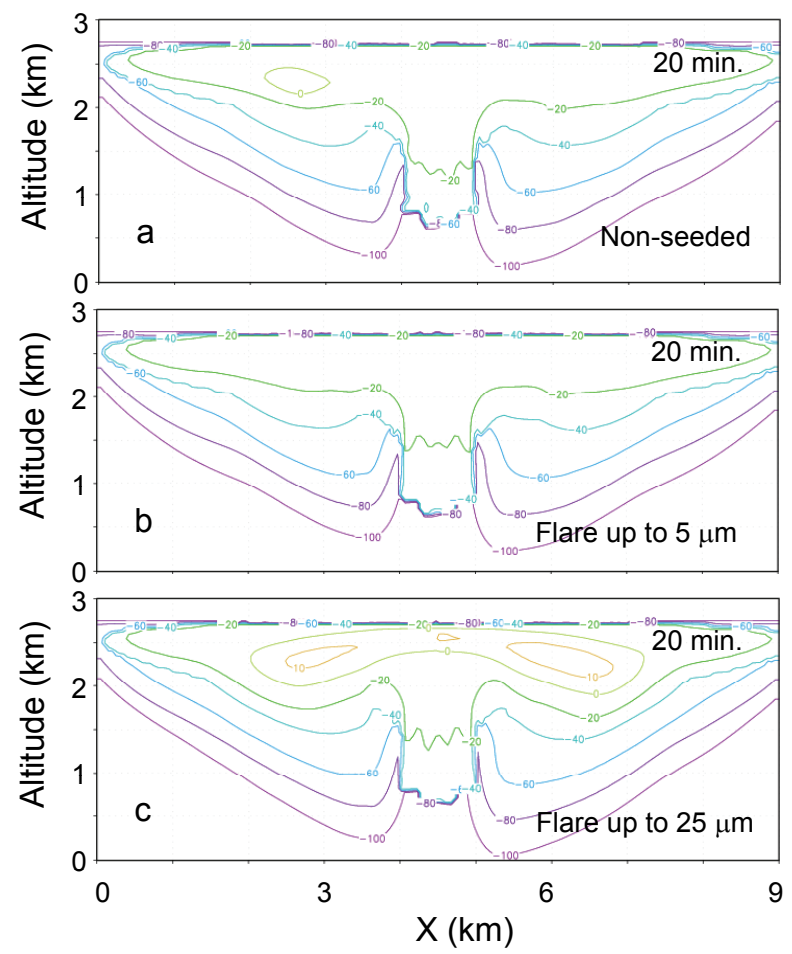

Fig. 16. Radar reflectivity in shallow convective cloud at $20 \mathrm{~min}$ for the non-seeded case (a) and seeded cases with flare particles $\left(970 \mathrm{~cm}^{-3}\right)$ up to $5 \mu \mathrm{m}$ (b) and up to $25 \mu \mathrm{m}$ (c).
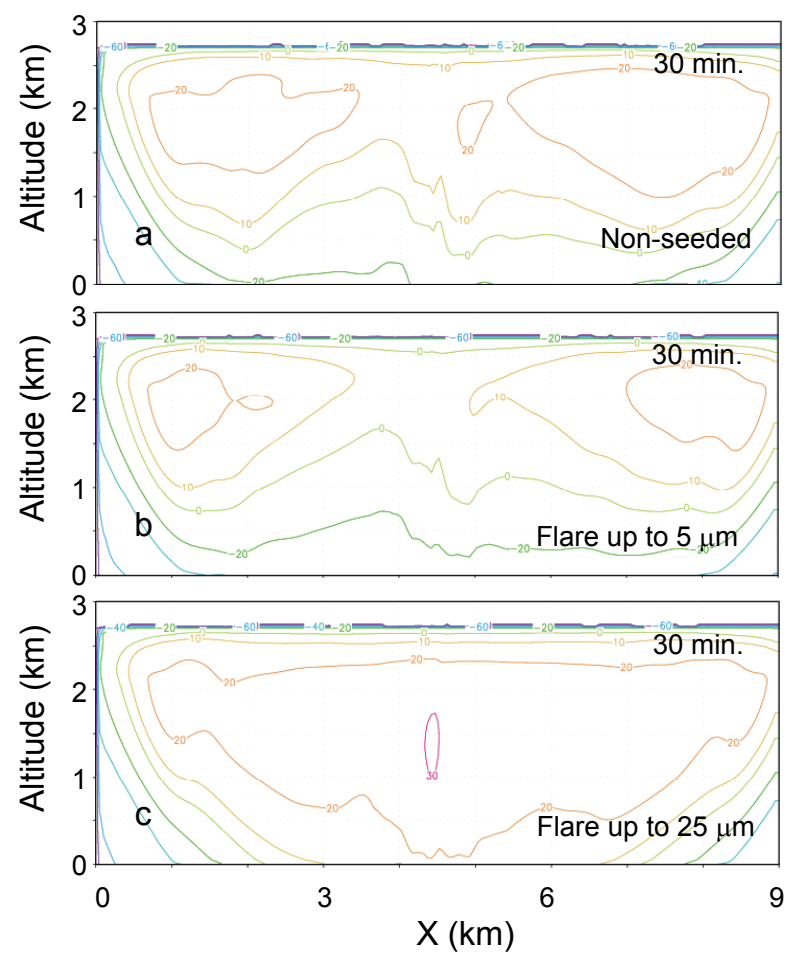

Fig. 17. Same as Fig. 16 except at $30 \mathrm{~min}$. 

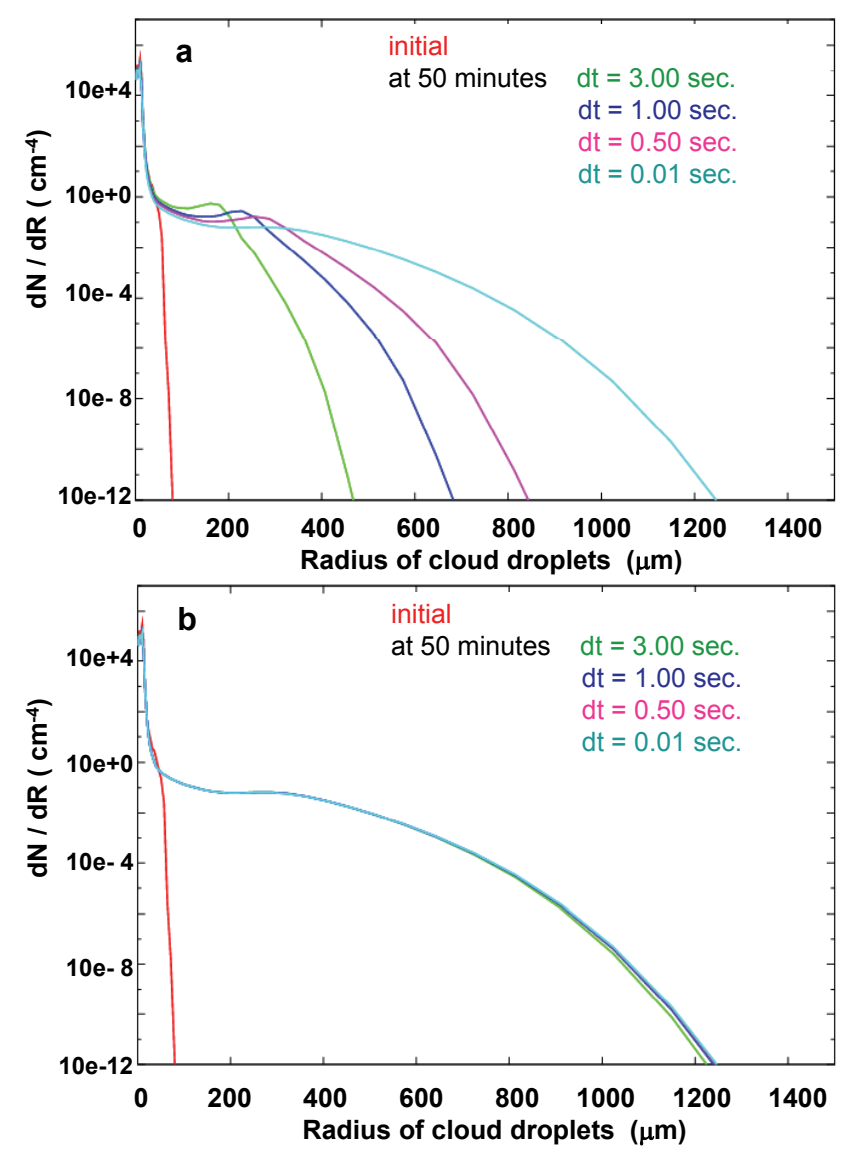

Fig. A1. Cloud droplet size distributions at the initial stage (red line) and at $50 \mathrm{~min}$. Cloud droplets are assumed to grow only by coalescence. Each line shows the droplet size distribution calculated with different time steps: $3 \mathrm{~s}$ (green line), $1 \mathrm{~s}$ (blue line), $0.5 \mathrm{~s}$ (pink line), and $0.01 \mathrm{~s}$ (light blue line). (a) Coalescence is estimated using only the general stochastic coalescence scheme in which multiple coalescence in one time step is neglected. (b) Coalescence is estimated by the special scheme used in this study, including both general stochastic coalescence and continuous coalescence schemes.

collision-coalescence mechanism. We used a special treatment to accurately calculate the collision-coalescence growth of cloud droplets following the doctoral dissertation of JenPing Chen (1992).

Given $P(i, j)$ as the probability (or number) of coalescence of a droplet in the $i$-th bin with droplets in the $j$-th bin for one time step (radius $(i)>\operatorname{radius}(j)$ ), if $\sum_{j=1}^{i} P(i, j) \leq 1$, coalescence between droplets in the $i$-th bin and $j$-th bin is estimated by a general stochastic coalescence scheme. If $\sum_{j=1}^{i} P(i, j)>1$ and $\sum_{j=k}^{i} P(i, j) \leq 1$, coalescence between droplets in the $i$-th bin and $k,(k+1),(k+2), \ldots,(i-1)$, or $i$-th bin is estimated by a general stochastic coalescence scheme, and coalescence between droplets in the $i$-th bin and $1,2, \ldots,(k-2)$ or $(k-1)$-th bin is estimated by a continuous coalescence scheme. This means that $N(i) P(i, j)$ droplets in the $j$-th bin $[j=1 \sim(k-1)]$ are evenly shared by droplets in the $i$-th bin. Figure A1 presents the cloud droplet size distribution at the initial stage and at $50 \mathrm{~min}$, during which time cloud droplets are assumed to grow by only coalescence. The results in Fig. A1a are from numerical simulation using only the general stochastic coalescence scheme in which multiple coalescence in one time step is neglected. Each line shows size distributions obtained from numerical simulations with time steps of $3 \mathrm{~s}$ (green line), $1 \mathrm{~s}$ (blue line), $0.5 \mathrm{~s}$ (pink line), and $0.01 \mathrm{~s}$ (light blue line). We can see that the larger time steps lead to larger underestimations of coalescence growth. Figure A1b shows the results of numerical simulation using the special scheme applied in this study including the general stochastic coalescence scheme and continuous coalescence scheme. Underestimation of coalescence growth is negligibly small, even if the 3-s time step is used.

Acknowledgements. The authors sincerely thank Ryohei Misumi of the National Research Institute for Earth Science and Disaster Prevention (NIED), who supplied Fortran code for the breakup process. This study was carried out as a part of the Japanese Cloud Seeding Experiments for Precipitation Augmentation (JCSEPA) funded by the Ministry of Education, Culture, Sports, Science and Technology, Japan, under the Special Coordination Funds for Promoting Science and Technology.

Edited by: G. Feingold

\section{References}

Albrecht, B. A., Bretherton, C. S., Johnson, D., Scubert, W. H., and Frisch, A. S.: The Atlantic stratocumulus transition experiment - ASTEX, B. Am. Meteorol. Soc., 76, 889-904, 1995.

Biswas, K. R. and Dennis, A. S.: Formation of a rain shower by salt seeding, J. Appl. Meteorol., 10, 780-784, 1971.

Bowen, E. G.: The formation of rain by coalescence, Aust. J. Sci. Res. Ser. A, 3, 193-213, 1950.

Bowen, E. G.: A new method of stimulating convective clouds to produce rain and hail, Q. J. Roy. Meteor. Soc., 78, 37-45, 1952.

Chen, J.-P.: Numerical simulation of the redistribution of atmospheric trace chemicals through cloud processes, Ph.D. desertation, The Pennsylvania State University, 343 pp., 1992.

Chen, J.-P. and Lamb, D.: Simulation of cloud microphysics and chemical processes using a multicomponent framework, Part I: Description of the microphysical model, J. Atmos. Sci., 51, 2613-2630, 1994.

Caro, D., Wobrock, W., and Flossmann, A. I.: A numerical stydy on impact of hygroscopic seeding on the development of cloud particle spectra, J. Appl. Meteorol., 41, 333-350, 2002.

Cooper, W. A., Bruintjes, R. T., and Mather, G. K.: Calculations pertaining to hygrospic seeding with flares, J. Appl. Meteorol., 36, 1449-1469, 1997.

Cotton, W. R.: Modification of precipitation from warm clouds - A review, B. Am. Meteor. Soc., 63, 146-160, 1982. 
Feingold, G., Tzivion, S., and Levin, Z.: Evolution of raindrop spectra, Part I: Solution to the stochastic collection/breakup equation using the method of moments, J. Atmos. Sci., 45, 3387-3399, 1988.

Feingold, G., Stevens, B., Cotton, W. R., and Frisch, A. S.: The relationship between drop in-cloud residence time and drizzle production in numerically simulated stratocumulus clouds, J. Atmos. Sci., 53(8), 1108-1122, 1996.

Feingold, G., Cotton, W. R., Kreidenweis, S. M., and Davis, J. T.: The impact of giant cloud condensation nuclei on drizzle formation in stratocumulus: implications for cloud radiative properties, J. Atmos. Sci., 56(15), 4100-4117, 1999.

Feingold, G. and Siebert, H.: Cloud-aerosol interactions from the micro to the cloud scale, Chapter in Strungmann Forum report, Cambridge, The MIT press, vol. 2, 2009.

Ghan, S. J., Guzman, G., and Abdul-Razzak, H.: Competition between sea salt and sulfate particles as cloud condensation nucle, J. Atmos. Sci., 55, 3340-3347, 1998.

Grabowski, W. W. and Wang, L.-P.: Diffusional and accretional growth of water drops in a rising adiabatic parcel: effects of the turbulent collision kernel, Atmos. Chem. Phys., 9, 2335-2353, 2009 ,

http://www.atmos-chem-phys.net/9/2335/2009/.

Kuba, N. and Takeda, T.: Numerical Study of the effect of CCN on the size distribution of cloud droplets, Part II: Formation of large droplets, J. Meteorol. Soc. Jpn., 61(3), 375-387, 1983.

Kuba, N. and Fujiyoshi, Y.: Development of a cloud microphysical model and parameterizations to describe the effect of CCN on warm cloud, Atmos. Chem. Phys., 6, 2793-2810, 2006, http://www.atmos-chem-phys.net/6/2793/2006/.

Mather, G. K., Terblanche, D. E., Steffens, F. E., and Fletcher, L.: Results of the South African cloud-seeding experiments using hygroscopic flares, Boston, MA, J. Appl. Meteorol., 36(11), 1433-1447, 1997.

Morrison, H. and Grabowski, W. W.: Comparison of bulk and bin warm rain microphysics models using a kinematic framework, J. Atmos. Sci., 64, 2839-2861, 2007

Murty, A. S. R., Selvam, A. M., Devara, P. C. S., et al.: 11-year warm cloud seeding experiment in Maharashtra State, India, J. Weather Mod., 32, 10-20, 2000.

O’Dowd, C. D., Lowe, J. A., Smith, M. H., and Kaye, A. D.: The relative importance of non-sea-salt sulphate and sea-salt aerosol to the marine cloud condensation nuclei population: An improved multi-component aerosol-cloud droplet parametrization, Q. J. Roy. Meteor. Soc., 125, 1295-1313, 1999.
Reisin, T., Tzivion, S., and Levin, Z.: Seeding convective clouds with ice nuclei or hygroscopic particles: A numerical study using a model with detailed microphysics, J. Appl. Meteorol., 35, 1416-1434, 1996.

Saleeby, S. M. and Cotton, W. R.: A large-droplet mode and prognostic number concentration of cloud droplets in the Colorado State University Regional Atmospheric Modeling System (RAMS), Part I: Module descriptions and supercell test simulations, J. Appl. Meteorol., 43, 182-195, 2004.

Segal, Y., Khain, A., Pinsky, M., and Rosenfeld, D.: Effects of hygroscopic seeding on raindrop formation as seen from simulations using a 2000-bin spectral cloud parcel model, Atmos. Res., 71, 3-34, 2004.

Segal, Y., Pinsky, M., and Khain, A.: The role of competition in raindrop formation, Atmos. Res., 83, 106-118, 2007.

Seifert, A., Khain, A., Blahak, U., and Beheng, K. D.: Possible effect of collisional breakup on mixed-phase deep convection simulated by a spectral (bin) cloud model, J. Atmos. Sci., 62, 19171931, 2005.

Smolarkiewicz, P. K.: A fully multidimensional positive definite advection transport algorithm with small implicit diffusion, J. Comput. Phys., 54, 325-362, 1984.

Szumowski, M. J., Grabowski, W. W., and Ochs III, H. T.: Simple two-dimensional kinematic framework designed to test warm rain microphysical models, Atmos. Res., 45, 299-326, 1998.

Takeda, T. and Kuba, N.: Numerical study of the effect of CCN on the size distribution of cloud droplets, Part I.: Cloud droplets in the stage of condensation growth, J. Meteorol. Soc. Jpn., 60(4), 978-993, 1982.

Teller, A. and Levin, Z.: The effects of aerosols on precipitation and dimensions of subtropical clouds: a sensitivity study using a numerical cloud model, Atmos. Chem. Phys., 6, 67-80, 2006, http://www.atmos-chem-phys.net/6/67/2006/.

Tzivion, S., Reisin, T., and Levin, Z.: Numerical simulation of hygroscopic seeding in a convective cloud, J. Appl. Meteorol., 33, 252-267, 1994.

WMO: Report on the WMO International Workshop on Hygroscopic Seeding: Experimental results, physical processes, and research needs, WMP Rep. 35, WMO/TD Rep. 1006, WMO, 68 pp., 2000.

Yin, Y., Levin, Z., Reisin, T., and Tzivion, S.: Seeding convective clouds with hygroscopic flares: Numerical simulations using a cloud model with detailed microphysics, J. Appl. Meteorol., 39, 1460-1472, 2000.

Yin, Y., Levin, Z., Reisin, T. G., and Tzivion, S.: The effect of giant cloud condensation nuclei on the development of precipitation in convective clouds - a numerical study, Atmos. Res., 53, 91-116, 2000b. 